\title{
Design, Implementation and Assessment of a Web-Based Ethnomathematics Instructional Content Repository for Mathematics Teachers in Benue State, Nigeria
}

\author{
Joshua Abah Abah ${ }^{1,2 \star}$, Clement Onwu Iji $^{1}$, Benjamin Ogbole Abakpa ${ }^{1}$, Paul Igber Anyagh ${ }^{1}$
}

\author{
${ }^{1}$ Joseph Sarwuan Tarka University, Makurdi, NIGERIA \\ ${ }^{2}$ Network for Grassroots Science and Mathematics Education (The VillageMath Network), NIGERIA \\ *Corresponding Author: abahjoshua.a@gmail.com
}

Citation: Abah, J. A., Iji, C. O., Abakpa, B. O., \& Anyagh, P. I. (2021). Design, Implementation and Assessment of a Web-Based Ethnomathematics Instructional Content Repository for Mathematics Teachers in Benue State, Nigeria. Journal of Mathematics and Science Teacher, 1(1), em002. https://doi.org/10.29333/mathsciteacher/11075

\section{ARTICLE INFO}

Received: 1 May 2021

Accepted: 19 Jun. 2021

\begin{abstract}
This study developed and assessed a web-based ethnomathematics instructional content repository for pre-service and in-service mathematics teachers in Benue State, Nigeria. The study adopted a developmental research design to systematically build and evaluate the educational intervention as a solution to complex problems in mathematics education practice. The development was achieved using WordPress Version 5.4, hosted online at https://villagemath.net on Linux OS server running with cPanel v80.p (Build 20), Apache Version 2.4.39, PHP Version 5.6.40 and MySQL Version 5.7.26. The study was guided by seven research questions posed around common web metrics, key performance indices, and quality assessment in terms of content, navigation, structure, appearance and uniqueness of the designed web tool. Five hypotheses were formulated and tested at 0.05 level of significance using t-test. The sample for the study comprises 341 pre-service and in-service mathematics teachers drawn from a population of 2981 using purposive sampling. The main instrument of the study is the researcher-developed Web-based Ethnomathematics Instructional Content Repository Assessment Questionnaire - WEICRAQ (Cronbach Alpha Coefficient $=0.98$, indicating a high level of internal consistency of the instrument). Additional data collection was handled using WP Statistics, Pingdom Tools, Google PageSpeed Insights, GTmetrix and WebPage Test. The research questions were answered using charts, graphs, mean and standard deviation. Analysis of the results of the study yielded a positive pattern of common web metrics for the designed web tool, indicating that the platform appeals to a wide range of users, with key performance indicators such as speed index, page size, and last painted hero affirming that the platform is robust, elegantly designed and fast. The results also showed that pre-service and in-service mathematics teachers in Benue State, Nigeria unanimously rated the Web-based Ethnomathematics Instructional Content Repository high in terms of content, navigation, structure, appearance and uniqueness. The outcomes of this study has demonstrated that culture can indeed become an integral part of every aspect of instructional design, making it important to consider social and cultural peculiarities in planning and delivering mathematics instruction. The Web-based Ethnomathematics Instructional Content Repository has humanized Mathematics for users and provided a reservoir of resources for training students in conceptual understanding, procedural fluency, strategic competence, adaptive reasoning and productive disposition. Based on the findings of the study, it was recommended that Mathematics teachers should continue to use the Webbased Ethnomathematics Instructional Content Repository as a worthy companion tailored to their specific professional needs, and that students across all levels of education should seek deeper and more enriched learning experience by continuously leveraging on instructional resources available on the web tool to enhance their individualized learning, enrich their cultural rediscovery, and add aesthetic value to their learning of Mathematics as a school subject. It was also recommended that Mathematics educators in colleges of education and universities should deploy the instructional environment as a veritable tool for re-directing narratives across the field of Mathematics Education, and that Nongovernmental organizations (NGOs) and government agencies in the educational and cultural sectors should make use of the ethnomathematics platform to drive their initiatives in grassroots development.
\end{abstract}

Keywords: mathematics education, ethnomathematics, VillageMath, instructional design, WordPress

\section{INTRODUCTION}

Mathematics is an original tool of the society, crafted by man to aid human existence. The teaching of the subject is, therefore, expected to inculcate in learners certain modes of thinking that are quite important in the successful building of the society and the nation. The analytical approaches of Mathematics enhance learners' ability to take hold of a situation, to analyze the situation and to perceive 
correctly the state of affairs (Thomaskutty \& George, 2007). Consequently, to attain the societal expectation of Mathematics, the subject must be embedded in the culture of the people it serves.

The heritage of every society shows that culture consists of an ensemble of religion, philosophy and arts. Political organization, moral or ethical views, judgments, the principles of democracy and citizenship, languages, music, sportsmanship and games, are all components of culture as is Mathematics, science, and to an increasing extent in today's world, technology (Sidjanski, 2010). Culture reflects how people live, behave, dress, eat, drink, rear children and maintain societal relationship. Thomaskutty and George (2007) observe that culture is greatly determined by the scientific and technological advancement of the society, which in turn depends upon the progress and development of Mathematics. Thus, the entire history of Mathematics portrays the culture and civilization of the society and the role Mathematics plays in the preservation and transmission of tradition.

Mathematics exists as a body of truth about relationships between abstract entities and structures. These abstract relationships are reflected or instantiated in various forms and at different levels in the concrete structure of the physical world. Even in its most complex form, Mathematics as a subject is rooted in reality with applications in everyday life (Abah, 2016). Many people, including parents, teachers and students, believe that Mathematics is a collection of fixed truths and unchangeable laws, which relegates Mathematics to an abstract contraption clamped with long formulae and mechanical processes. The days of such misconception have passed and the focus is now on the meaning of what children learn and their application in day-to-day life. Newer perspectives in Mathematics have been emerging in order to make Mathematics meaningful to learners, their parents and teachers, and their community (United Nations Education Scientific and Cultural organization - UNESCO, 2008). Such perspectives have carved out the field of Ethnomathematics, one of the innovative ideas of Mathematics education that identifies meaning in everyday activities of ordinary people and looks for the implication for lifelong learning.

The idea of Mathematics as it used to be known is splintered when the prefix "ethno" is associated to it. "Ethno" shifts Mathematics from places where it has been erected and glorified (universities and schools) and spread it to the world of people, in their diverse cultures and everyday activities (Domite \& Pais, 2009). Ethnomathematics as an approach sullies Mathematics with the human factor, a "human" situated in a space and time with diverse knowledge and practices. The approach does not restrict its reach to the mathematical knowledge of culturally distinct people, or people in their daily activities, but could focus on academic Mathematics through a social, historical, political and economic analysis of how Mathematics has become what it is today. Within this viewpoint, Ethnomathematics seeks to understand the historical development of Mathematics as a scientific discipline, the understanding of that development as the intersection between knowledge from different cultures and the validation of what is considered to be true mathematical knowledge (Abah, lji, \& Abakpa, 2018).

The application of ethnomathematical approaches allows the opportunity to examine local knowledge systems and give insight into forms of Mathematics used in diverse contexts and cultural groups. The pedagogical approach that connects this diversity of Mathematics is best represented by a process of translation and elaboration of the problems and questions taken from daily phenomenon. The ideas generated from real life attachments to mathematical concepts can truly create conflictive situations in which students are encouraged to reflect upon the rules that define their action when dealing with the concepts (Bernardes \& Roque, 2015). This classroom approach results in both sensitive and historical thinking, mediated by bodies, signs, artefacts and cultural meanings (Guillemette, 2015), giving rise to a non-mentalist conception of thought (Abah, 2016).

Ethnomathematics has a broad meaning. As well as describing mathematical symbolizations, applications and practices which are culturally distinct, it will be assumed to include mathematical concepts, systems, modes of thinking and meta-mathematics, such as what counts as proof, beliefs about how Mathematics relates to the world and values implicit in Mathematics (Abah, 2018b). In the view of the early proponents of ethnomathematics (including Ubiratan D'Ambrosio), if ethnomathematics aspired to be more than just the study of different mathematical ideas, but also the critical study of social, political and anthropological aspects of academic Mathematics, then it must assume itself a critical stance on how Mathematics is involved in the maintenance of the modern world (Domite \& Pais, 2009). Ethnomathematics wishes to be an epistemological and educational alternative to modern Mathematics as well as forming the basis for enlightenment in science and technology.

By adopting ethnomathematics as an instructional paradigm, several studies have been able to affirm enhanced mathematical literacy, increased psychological motivation and linguistic and transverse competencies (Abah, 2018a). Troutman and McCoy (2008) report improved students' attitude after introducing culturally relevant Mathematics history lesson in an Algebra class comprising of diverse racial background. When history of Mathematics was used to teach volume formula of frustum pyramids, students found the activities interesting as well as instructing (Butuner, 2015). The usage of original ethnomathematical sources, for instance, has been shown to be effective in the teaching and learning of Mathematics (Guillemette, 2015). In a similar study, aimed at determining first year students' reflections when Fibonacci tiling, the ancient Chinese Fang Cheng procedures, and the ancient Indian meru prastara recursions were introduced as historical snippets in an adventure pedagogy for basic Mathematics, Abah (2017) reports that the artefacts aid in concretizing of concepts, spurring of behavioural engagement in learners, adding of aesthetic value to Mathematics, sustaining of students attention, computational ease and effective recall of mathematical procedures. In a related work exploring the cultural richness of a Christmas carol, Twelve Days of Christmas, Abah (2018a) demonstrates that when poetry-based artefacts are deployed in instructional contexts, they allow team building, aid recall, reinforce mathematical thinking process, connect history and the real world, and humanize Mathematics for all students. Other mathematically relevant cultural activities such as festivals, dances, bedtime stories, indigenous artworks, local architectures, and games have also been shown to contain rich educational relevance for the Mathematics classroom (Abah, 2018b).

The implications of most research findings in the ethnomathematics sub-field indicate that the sustainable conception of Mathematics incorporates not only Mathematics content knowledge (i.e., rules and algorithms) but a meaningful Mathematics content base (knowing the why and how of Mathematics) and teacher's attitude towards Mathematics (Anyagh, Honmane, \& Abah, 2018; Burns, 2010). For teachers in particular, the conceptual history of Mathematics allows them to understand why certain concepts are difficult to 
understand (Heeffer, 2006). Butuner (2015) observes that when researchers discuss their reasons for using the ethnomathematics approach in the classroom, they mostly state that the approach will reduce students' anxiety about Mathematics, increase their motivation and attitudes towards learning, help them learn the subject and concepts, and reveal the multicultural, developing and dynamic structure of Mathematics. The line of thinking from these empirical researches allows Mathematics educators to reassert theoretical conjectures and give new ideas for future lines of research in ethnomathematics (Costa, Alves \& Guerra, 2015). The call for innovative studies imbibing the ethnomathematics approach to Mathematics instruction will continue to be an open-ended one, particularly when considered in the light of modern technology.

Using the principles of culture-based Mathematics education, a few research efforts have reported blended technologies for learning in a local cultural context. Vainio, Walsh, and Varsaluoma (2014) consider the impact of culturally sensitive issues in the design of mobile Mathematics learning service in a longitudinal research with over thirty (30) South African schools across a three-year period. The platform designed as part of Nokia Mobile Mathematics deployed SMS-based applications, a mobile browser and a mobile social network, MXit, to deliver learning context including bookwork with content explanations, examples, exercises, homework questions and competitions. Within the project, teachers could use the exercise bank and theory for in-class teaching in follow-up, analyzing and monitoring how the pupils make progress. Overall, Vainio et al. (2014) found subjective and objective culturally dependent issues in the content, context, infrastructure and technology of the platform with the localization enhancing the user experience and supporting learning.

Similar attempt by Katmada, Mavridis, and Tsiatsos (2014) focuses on the design, implementation and evaluation of online game for elementary and middle school Mathematics, with outcome redefining flexibility, adaptability and usability of web-based gaming tools. Relatedly, Govaerts et al. (2015) provide reports on the development of the Go-Lab Tutoring Platform that offers teachers an online peer assistance and knowledge sharing environment, with the results of the prototype proving the concept as a promising solution to support teachers with bringing online labs into the classroom. Through the evaluation, the study investigated incentives to motivate teachers and tutors, providing an indication for a potential business model to involve diverse stakeholders, including ministries of education, teacher professional development organizations, teachers and STEM teacher community. Other instrumentation studies which sought to create learning environments for indigenous students through culture-based Mathematics modules conclude that implementation through culture-based Mathematics instructional modules could motivate students' interest in learning Mathematics and enhance their initiatives in the classroom (Garmpis, 2011; Jung, Jun, \& Gruenwald, 2001; Kartam \& Al-Rashaid, 2002; Ofoegbu et al., 2014; Yao, 2016).

Despite the prospects of culture-based instructional design and the enormous benefits accruable from optimal blends of culture and technology, there is a scarcity of research attempts on the ethnomathematical approach from within Nigeria. Phenomenal works such as Abah (2017), Iluno and Taylor (2013), Kurumeh, Onah, and Mohammed (2012), and Yusuf, Saidu, and Halliru (2010), though robust in the ethnomathematical sense, fell short of extending culture-based solutions to the cyberspace. Considering the fact that present-day students are a new genre of students with learning needs vastly different from their predecessors (Thomas, 2011) and live in a culture of learning, leisure and social interaction (Iji, Abah, \& Anyor, 2017), current research efforts need to explore the intricacies of using technology to give voice to indigenous knowledge systems in Mathematics education. Such research intervention in Mathematics education should basically prepare teachers to become innovative Mathematics instructors, professionally prepared to communicate Mathematics to learners at all levels (lji, Abah, \& Anyor, 2018).

In the light of the promise of individualized learning available in a widely connected educational cloud, there is the need for a custommade, web-based product for Mathematics education practitioners in Benue State, Nigeria. Such a product must be designed with respect to the cultural foundations of Mathematics, with particular reference to the indigenous people of Benue State, although future enhancement may encompass Nigeria, Africa and the world by the addition of components that will be multicultural and more diversified. These specific needs form the basis of this study around the development of a web-based ethnomathematics instructional content repository. This tool is intended to be a one-stop reservoir of online resources that are tailored to the peculiarities of Mathematics education as a field of practice in Benue State, Nigeria. The repository is intended to gather digital contents that are rooted in the culture of the different ethnic groups living in Benue State.

Specifically, the digital contents of such repository includes instructional articles, crowd-sourced blog articles, culture-based teaching approaches and lesson plans, instructional procedures for including local artifacts in Mathematics instruction, adaptations of local mathematical games, community based forums, social media and links to other Mathematics instructional platforms. The development of the online repository is to showcase the beauty of the Mathematics existing all around students and to draw attention of in-service and pre-service Mathematics teachers to pedagogies that effectively blend everyday Mathematics into classroom practice. The repository is targeted at making Mathematics more realistic, particularly, with reference to the cultural context of the subject in Benue State, North Central Nigeria.

\section{STATEMENT OF THE PROBLEM}

Mathematics is chief among disciplines in terms of its rich cultural and historical roots in the practices of ordinary people. This is because Mathematics is always adapting to the needs of the society. Despite the simple origins of Mathematics, it has been reduced to a very abstract subject and mystified to students by poor teaching approaches in schools. A large part of the education system has rendered Mathematics as the rigid privilege of a few enlightened students, leaving behind a poor attitude towards the subject across early childhood, basic, secondary and tertiary education.

A way out of the plethora of issues bedeviling the teaching and learning of Mathematics is a concerted effort to promote the image of the subject as a vivid discipline with links to reality. Mathematics in its present form came about as diverse cultural groups sought to resolve unique problems such as daily living, exploration, colonization, communications and commerce. The realization that every culture generates its own ways of explaining, understanding and coping with reality gave rise to ethnomathematics as a view point in Mathematics 


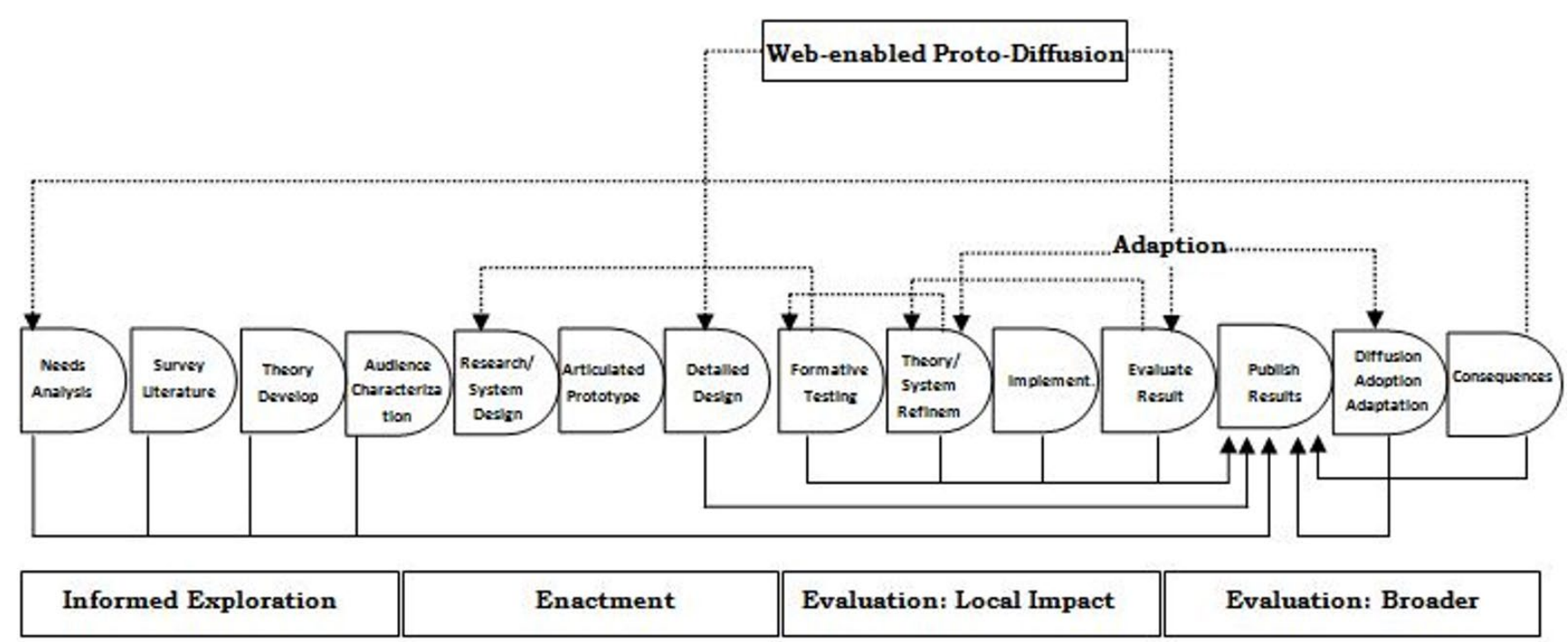

Figure 1. The Integrative Learning Design Framework (Source: Bannan-Ritland, 2003)

education. The application of ethnomathematical approaches allows the opportunity to examine indigenous knowledge systems and give insight into forms of Mathematics used in diverse contexts and cultural groups.

After many years of propagating Mathematics so loaded with techniques, skills, as if belonging to a universe different from ours, modern Mathematics education calls for deployment of readily available technologies to seamlessly deliver culture-based Mathematics instruction, support curricular goals and provide a deeper understanding of Mathematics content. In line with this call, the present study seeks to build a robust ethnomathematics instructional content repository for use by pre-service and in-service Mathematics teachers in Benue State, Nigeria. How does this web-based tool measure up in terms of key performance indicators? What are the perceptions of practitioners on the quality of this online instructional platform? What is the pattern of acceptability of the web-based ethnomathematics instructional content repository among the wide range of end-users? These, pertinent concerns, form the basis of this study.

\section{THEORETICAL FRAMEWORK}

\section{Integrative Learning Design Framework (Bannan-Ritland, 2003)}

The Integrative Learning Design Framework emerged out of the work of Brenda Bannan- Ritland at the breaking of the twenty-first Century. Bannan-Ritland (2003) proposed an Integrative Learning Design (ILD) framework that attempts to provide a comprehensive, yet flexible, guiding framework that positions design research as a socially-constructed, contextualized process for producing educationally effective interventions with a high likelihood of being used in practice. The goal of the ILD framework is not only to construct propositions about learning and teaching but also to engineer and construct effective learning environments using software and other artefacts that allow teachers and learners to make these propositions actionable.

Extending the stages of Ulrich and Eppinger (2000) and drawing upon other design fields, the broad phases of the ILD framework are:

i. Informed Exploration

ii. Enactment

iii. Evaluation: Local Impact

iv. Evaluation: Broader Impact.

\section{The Informed Exploration Phase of ILD}

From the outset, and prevailing all four phases of ILD, is concern with identifying and satisfying the needs of the intended users so that the mature innovation is successfully adopted and used to support its learning goals (Bannan-Ritland, 2003). This first phase of ILD, therefore, is rooted in essential research steps of problem identification, literature survey and problem definition. To this foundation, ILD framework adds (a) a needs analysis activity from the field of instructional system design and innovation development, and (b) a research focus on audience characterization from the field of usage-centred design (See Figure 1).

With respect to the current study, the Informed Exploration phase of the ethnomathematics instructional content repository project focused on the problem of existing approaches to mathematics instruction that have continually stunted students' growth and attitude within the subject. The development project carried out traditional literature review, supplemented with a benchmarking of related products. This needs analysis results in a distinction between existing e-learning platforms and the present work. Unlike most online instructional platforms, the present project does not entail course delivery and grading. Instead, the focus is to build a robust ethnomathematics instructional content repository that can draw attention to the mathematics embedded in ordinary culture, traditions and daily practices. The overarching objective is to spur pre-service and in-service mathematics teachers to a quest to rediscover the practices that have been generated or learned by our ancestors, transmitted through generations, modified through a process of cultural 
dynamism and learned by them in more casual, less formal way. Thus, the outcome of the Informed Exploration Phase for the present work is a purposeful resolve and templates to build a reservoir of online resources that are tailored to the needs of culture-based mathematics education.

\section{The Enactment Phase of ILD}

The ILD framework views intervention as a socially-constructed object that must be systematically articulated and revised over a number of cycles rather than as a standard "treatment" intended to test hypotheses (Bannan-Ritland, 2003). In this sense, the Enactment phase is comprised of initial product design, prototype articulation and the subsequent development of a more fully detailed platform. Development in this phase is primarily influenced by evaluations conducted on the local relevance of the intervention. Bannan-Ritland (2003) maintains that nonetheless, when early prototypes are posted on the web, the Enactment phase may also be influenced by feedback from both solicited and unsolicited users of the intervention providing ongoing real-world input on design and development.

In relation to the ethnomathematics instructional content repository, value-adding feedbacks were obtained via comments on the project's Facebook page, Twitter handle, online forums such as Nairaland, and professional blogs such as Google's Medium. This phenomenon is described as "Web-enabled proto-diffusion" in ILD (See Figure 1). Consequently, the Enactment Phase may last for a considerable period of time and involve multiple design cycles (Bannan-Ritland, 2003).

\section{The Evaluation Phase: Local Impact}

In the ILD framework, evaluation is a two-stage phenomenon. The goal of the first stage is to evaluate the local impact of the intervention, by asking how well the designed product satisfies its target users. In the case of the ethnomathematics instructional content repository, the target users include pre-service and in-service mathematics teachers as well as mathematics educators. The goal of the second stage is to look at issues of ecological validity and successful dissemination and adoption in a broader context and to a broader audience (Bannan-Ritland, 2003).

Bannan-Ritland (2003) relates that at this stage, data collection and analysis are an iterative process in which formative evaluation of the intervention interacts with local theory development during an extended implementation phase including (at maturity) more summative evaluation of the study's results and products. Evidently, data collected in this phase may lead to substantial changes in the designed intervention, necessitating in some cases, revisiting the Enactment Phase. Further, data from unsolicited users of the (more mature) prototype (via the Web) may continue to inform design decisions (Bannan, 2010).

\section{The Evaluation Phase: Broader Impact}

The ILD framework extends the typical "dissemination" phase of educational research in which publication or presentation of findings is sometimes seen as a closure (Bannan-Ritland, 2003). ILD directs attention not only at publication but also at concerns related to the adoption and adaptation of researched practices and interventions. The framework also actively considers the consequences of the use of the products of the research. Data from dissemination, diffusion, adoption, adaptation and consequences are considered important not only for the current design or redesign study but also for the design of a programme of work that might span a decade or more (Bannan, 2010).

In the context of the present study, the implication of the final phase of the ILD framework is that the lifecycle of the designed ethnomathematics instructional content repository may last as long as improvements deem it possible. Subsequent refinements may thus be necessary, depending on the varying needs of users, proposals from early adaptors, and the expanding range of opportunities to be provided by new and future digital technologies. Such enhancements are also based on how well researchers and designers interventions satisfy the end-users and what educational and interactional effects the designed platform had (Nouri, Spikol \& CerrattoPargman, 2016). The lifecycle, therefore, must consider well-defined collaboration among mathematics teachers and the designer, particularly during implementation of the artefact (Iversen \& Jonsdottir, 2018).

For an online tool that intend to amplify the recognition that every cultural group generates its own mathematics, the ethnomathematics instructional content repository must crowd-source primary resources such as blog articles, tested classroom practices, culture-based lesson templates and other localized content from practicing mathematics teachers. Building on the tenets of the ILD framework, the platform must entail context-sensitive design elements gleaned from the numerous micro-communication processes in the teacher-researcher collaboration. Given the iterative nature of this culture-based project and the emerging needs of grassroots mathematics teachers, students and literacy facilitators that will use the Ethnomathematics Instructional Content Repository, the expectation is that the Repository design research will not terminate with diffusion, but will result in a consequences feedback loop, both positive and negative, expected and unexpected.

\section{Theory of Realistic Mathematics Education (Freudenthal, 1968)}

Realistic Mathematics Education is a domain-specific instruction theory for Mathematics. Basically, RME holds that rich, "realistic" situations are given prominent position in the learning process. These situations serve as a source for initiating the development of mathematical concepts, tools and procedures and as a context in which students can in a later stage apply their mathematical knowledge, which then gradually has become more formal and general and less context specific. Although "realistic" situations in the meaning of "real-world" situations are important in RME, "realistic" has a broader connotation here. The theory of Realistic Mathematics Education (RME) is credited to Hans Freudenthal (1905 - 1990), a mathematician born in Germany who in 1946 became a Professor of Pure and Applied Mathematics and the Foundations of Mathematics at Utrecht University in the Netherlands. Later in his career, Freudeenthal $(1968,1973,1991)$ became interested in Mathematics Education and argued for teaching Mathematics that is relevant for students and carrying out thought experiments to investigate how students can be offered opportunities for guided re-invention of Mathematics. 
One of the basic concepts of RME is Freudenthal's idea of Mathematics as a human activity. For him mathematics is not the body of mathematical knowledge, but the activity of solving problems and looking for problems, and more generally, the activity of organizing matter from reality or mathematical matter, which he called "mathematization" (Freudenthal, 1968). This activity-based interpretation of Mathematics has important consequences for how Mathematics Education was conceptualized. More precisely, it affected both the goals of Mathematics Education and the teaching methods (Van den Heuvel-Panhuizen, 2003). According to Freudenthal (1968, 1971, 1973), Mathematics can best be learned by doing and mathematizing is the core goal of mathematics education. Instead of presenting mathematics as a ready-made product, the goal should be to engage students in Mathematics as an activity. Then, similar to the way in which the mathematical activity of mathematicians has resulted in Mathematics as it is known, the activity of students should result in the construction of such Mathematics, in a way inventing Mathematics (Gravemeijer, 2008).

The tenets of RME distinguished between two ways of mathematizing in an educational context, namely "horizontal" and "vertical" mathematizing. In the case of horizontal mathematizing, mathematical tools are brought forward and used to organize and solve a problem situated in daily life. Vertical mathematizing, on the contrary, stands for all kinds of re-organizations and operations done by the students within the mathematical system itself. In the view of Freudenthal (1991), to mathematize horizontally means to go from the world of life to the world of symbols; and to mathematize vertically means to move within the world of symbols. The latter implies, for instance, making shortcuts and discovering connections between concepts and strategies and making use of these findings (Van den Heuvel Panhuizen, 2003). The emphasis in RME is that the two forms of mathematizing are of equal value, and could take place on all levels of mathematical activity.

Basically, ethnomathematics as a programme of mathematics education emphasizes the provision of realistic situations in the instructional process. The Ethnomathematics Instructional Content Repository is a tool which projects the mathematical concepts and knowledge embedded in the real lives of the learners as well as in the cultural practices of their people. Frequent reference to history of Mathematics and mathematics storytelling by the instructional platform offers problem situations that learners can imagine and relate to as experientially real in their minds (Abah, lji, \& Abakpa, 2018). The content coverage of the repository intends to humanize mathematics for users, pointing them to ways through which students can re-invent Mathematics for themselves.

In terms of mathematization, the educational product being developed in this study is a tool that can be creatively deployed to organize and solve problems situated in students' daily lives. That makes the platform an indispensable teacher-companion for horizontal mathematization. The blog articles, lesson plans, adaptable classroom activities and ethnomathematics forum provided by the webbased repository are to aid the Mathematics teacher to seamlessly move from the world of life to the world of mathematical symbols. The captivating activities provided on the platform follow that Mathematics is best learned by doing mathematics.

By building on the reality principle of RME, the Ethnomathematics Instructional Content Repository is designed to present resources that encourage Mathematics teachers to always start from problem situations that are meaningful to students and are derived from the learners' rich cultural contexts. Such approach allows for students to move from context-related situations to the constructing actionable mathematical strategies, stepping up through a spiral of intertwined curricular contents to achieve success. For learning and doing Mathematics, technology in the form of real-world interfaces such as the Ethnomathematics Instructional Content Repository can assist students' problem solving, support exploration of mathematical concepts, provide dynamically linked representations of ideas and can encourage general metacognitive abilities such as planning and checking (Barkatsas, 2004). Adaptable teaching templates available from the repository can aid the Mathematics teacher in providing the necessary guided re-invention and group discussions that will develop students' conceptual understanding, procedural fluency, strategic competence, adaptive reasoning and productive disposition (Kilpatrick \& Findell, 2001). Consequently, the web-based tool mediates for practicing mathematics teachers the process of constructing knowledge, with emphasis on pupils' hands-on activities and everyday life.

\section{RESEARCH QUESTIONS}

The following questions guide this study.

1. What are the patterns of common web metrics of the web-based ethnomathematics instructional content repository?

2. What are the key performance indicators of the web-based ethnomathematics instructional content repository?

3. To what extent do pre-service and in-service Mathematics teachers in Benue State rate the quality of the web-based ethnomathematics instructional content repository in terms of content?

4. To what extent do pre-service and in-service Mathematics teachers in Benue State rate the quality of the web-based ethnomathematics instructional content repository in terms of navigation?

5. To what extent do pre-service and in-service Mathematics teachers in Benue State rate the quality of the web-based ethnomathematics instructional content repository in terms of structure?

6. To what extent do pre-service and in-service Mathematics teachers in Benue State rate the quality of the web-based ethnomathematics instructional content repository in terms of appearance?

7. To what extent do pre-service and in-service Mathematics teachers in Benue State rate the quality of the web-based ethnomathematics instructional content repository in terms of uniqueness?

\section{RESEARCH HYPOTHESES}

The following research hypotheses were formulated and tested at 0.05 level of significance. 
1. There is no significant difference in the mean ratings of pre-service Mathematics teachers and in-service Mathematics in Benue State on the quality of the web-based ethnomathematics instructional content repository in terms of content.

2. There is no significant difference in the mean ratings of pre-service Mathematics teachers and in-service Mathematics in Benue State on the quality of the web-based ethnomathematics instructional content repository in terms of navigation.

3. There is no significant difference in the mean ratings of pre-service Mathematics teachers and in-service Mathematics teachers in Benue State on the quality of the web-based ethnomathematics instructional content repository in terms of structure.

4. There is no significant difference in the mean ratings of pre-service Mathematics teachers and in-service Mathematics teachers in Benue State on the quality of the web-based ethnomathematics instructional content repository in terms of appearance.

5. There is no significant difference in the mean ratings of pre-service Mathematics teachers and in-service Mathematics teachers in Benue State on the quality of the web-based ethnomathematics instructional content repository in terms of uniqueness.

\section{METHODOLOGY}

\section{Research Design}

The research design adopted for the study is developmental research design. This research blueprint is suitable for design-based researches, including studies of instructional design and development (Ritchey, Klein, \& Nelson, 2004). Developmental research is a process that integrates design and scientific methods to allow researchers to generate useful products and effective theory for solving individual and collective problems of education (Easterday, Lewis, \& Gerber, 2014). Developmental research envisions a tighter, more rigorous connection, between learning principles and features of the educational innovation. In design research, researcher's rigorous analysis of a learning problem leads to quite specific ideas for interventions. Designers then build systems that use information technology to build specific teaching and learning materials and methods designed to realize learning gains predicted by theory and research (Walker, 2006). Thus, developmental research is the systematic procedure of designing, developing and evaluating educational interventions (such as programmes, teaching-learning strategies and materials, products and systems) as solutions for complex problems in educational practice, which also aims at advancing knowledge about the characteristics of these interventions and the process of designing and developing them (Plomp, 2010). The web-based ethnomathematics instructional content repository for pre-service and in-service mathematics teachers, which is the focus of this study, is a practical educational intervention being developed within the iterative cycles of developmental research design to enhance mathematics teachers' deployment of indigenous knowledge systems and give insight into forms of Mathematics used in diverse contexts and cultural groups around the Benue valley.

\section{Area of the Study}

The study was conducted in Benue State. The State is located in North Central region of Nigeria and borders with Nasarawa State to the North, Taraba State to the East, Ebonyi and Cross River States to the South, Enugu to the South West, and Kogi State to the West. The State stretches between longitude $7^{\circ} 47^{\prime}$ and $10^{\circ} 0^{\prime}$ East, and latitude $6^{\circ} 25^{\prime}$ and $8^{\circ} 8^{\prime}$ North. Benue State has a land mass of 33,955 square kilometers, with a population of 4,780,389 in 2006, now estimated at nearly five million (Benue State Government, 2015; Thisday, 2012).

The choice of Benue State for this study was based on the evidence from literature that students, mathematics teachers and other critical stakeholders of mathematics education in Benue, like their counterparts from other parts of Nigeria, display a form of postmodern social codes which has relegated ordinary culture-based mathematics activities to the background, thereby further mystifying the subject (Abah, lji \& Abakpa, 2018; Dankaro \& Agoom, 2015; Ezeigbo, 2013). Indigenous Benue generates its own particular mathematical knowledge by building on heritage, environment, religious beliefs, technological advances, artistic inclinations and how people make their living. Also, the choice was appropriate considering the global migration to an Information Age in which Benue as a State is not left out. The widespread deployment of digital technology among mathematics teachers and students within the State is evident even by simple observation. Hence providing a web-based platform to showcase the rich ethnomathematics of the peoples and culture of Benue will be a timely contribution.

\section{Population of the Study}

The population of the study is 2981 comprising pre-service mathematics teachers (mathematics education students) in universities and colleges of education in Benue State, Nigeria as well as in-service mathematics teachers at the Basic and Secondary Education levels across Benue State, Nigeria (Benue State Ministry of Education, Science and Technology, 2019, and Examination Office Records, 2019).

\section{Sample and Sampling Technique}

The sample for the study is 341 pre-service and in-service mathematics teachers in Benue State, Nigeria. The sample size was arrived at by applying Krejcie and Morgan (1970) table for sample determination.

Purposive sampling was used for the study. Purposive sampling was used to select 241 pre-service mathematics teachers and 100 inservice mathematics teachers who have been duly registered as users on the villagemath.net platform. Purposive sampling was used because only pre-service and in-service mathematics teachers who have access to the internet and have used the web-based ethnomathematics instructional content repository can assess the quality of the platform. 


\section{Instrument for Data Collection}

The instrument for data collection in this study was the Web-based Ethnomathematics Instructional Content Repository Assessment Questionnaire (WEICRAQ). The WEICRAQ is a user experience questionnaire adapted from a set of existing measures of website user experience including Measure of Perceived Visual Aesthetics of Websites (Lavie \& Tractinsky, 2004), WebQual Measure of Website Quality (Loiacono, Watson, \& Goodhue, 2002), Multi-dimensional Scale for Measuring User-perceived Web Quality (Aladwani \& Palvia, 2002), Measure of User's Perceived Portal Service Quality (Kuo, Lu, Huang \& Wu, 2005), Standardized User Experience Percentile Rank Questionnaire - SUPR-Q (Sauro, 2015), and Scale to Measure the Interactivity of Web Sites (Liu, 2003). The WEICRAQ is divided into six sections, namely $A, B, C, D, E$, and $F$.

Section A is tagged Basic Information and comprises prompts on respondents' category and location. Sections B, C, D, E and F seek to measure the quality of the web-based ethnomathematics instructional content repository in terms of content, navigation, structure and design, appearance and multimedia, and uniqueness respectively. The items of sections B to F are structured on a four-point scale of Very High, High, Low, and Very Low and was scored 4, 3, 2, and 1 respectively for positive items. The scoring for negative items are reversed after the order 1, 2, 3, and 4, for Very High, High, Low, and Very Low respectively. The WEICRAQ contains a total of 62 items, with sections $\mathrm{C}, \mathrm{D}$, and $\mathrm{F}$ comprising 13 items each, section E comprising 12 items, and section B comprising 11 items (Appendix A).

Additional data collection on web metrics and key performance indices (KPI) was handled using WP Statistics Version 12.6 .12 (WordPress 5.4 accompanying metric system) and third-party web performance assessment tools such as Pingdom Tools, Google PageSpeed Insights, GTmetrix, and WebPageTest. These four web metric platforms were chosen based on their industry standing, ease of use and the wide range of KPIs that they measure. Pingdom Tools test the speed of any website from seven ( 7 ) different locations (5 continents) strategically placed around the globe. A typical Pingdom test returns a performance letter grade, load time and page size. Google PageSpeed Insights indicate a performance score, first contentful paint, first meaningful paint, speed index, and time to interactive. GTmetrix reports a PageSpeed score, fully loaded time and total page size. WebPageTest provides a median run performance result accounting for load time, first contentful paint, speed index, last painted hero, fully loaded time and bytes in (i.e., page size).

\section{Validation of the Instrument}

The validation of the instrument for this study was done by two experts in Mathematics Education, two experts in Measurement and Evaluation, two pre-service mathematics teachers, two in-service mathematics teachers, two experts in Computer Science, one ICT expert, and a digital technology critic. The experts were requested to vet the instrument based on face validity, simplicity of language, and appropriateness of the constructed items in respect of the objectives of the study. Based on the recommendations of the experts, necessary modifications were made to the instrument. The validation yielded a total of 62 items after an initial effort of 70 items were subjected to thorough scrutiny. For instance, items that are similar in meaning to others were either rephrased or dropped completely. The term "users" in some of the items were replaced to the more appropriate term "Mathematics teachers" considering the intended respondents. Similarly, the word "information" in some of the items was changed to "ethnomathematics content" to reflect the central fOcUS of WEICRAQ.

\section{Reliability of the Instrument}

To ensure reliability, the WEICRAQ was trial-tested on 50 users of the web-based ethnomathematics instructional content repository. The online platform for administering the WEICRAQ uses restrictive measures to prevent multiple submissions of responses. On this basis, the 50 respondents used in the trial-testing are completely outside the sample for the study. Results obtained from the trial-testing were subjected to reliability analysis yielding a Cronbach's alpha coefficient of 0.98 for the entire WEICRAQ, indicating a high level of internal consistency of the instrument. Cronbach's alpha is considered a suitable measure of internal consistency of WEICRAQ because the items are structured on a four-point scale. The reliability analysis was executed on Microsoft Office Excel.

\section{Method of Data Collection}

The WEICRAQ was administered to pre-service and in-service mathematics teachers in Benue State, Nigeria in online mode. The online survey uses a list-based frame of pre-service and in-service mathematics teachers in Benue State who have been verified as users on the villagemath.net platform. These users constitute a homogenous group for which a frame with phone numbers and email addresses has been assembled. The link to WEICRAQ was sent via SMS and/or email to the verified pre-service and in-service mathematics teachers. Email and phone contact information of respondents were provided voluntarily by villagemath.net users and were handled with utmost confidentiality.

The instrument is designed on JotForm and accessible via a link on the main menu of the villagemath.net platform. JotForm uses cookies, unique IPs and other security measures to implement restrictions and prevent duplicate submission of WEICRAQ. The choice of this mode of deployment hinges on the fact that the Web-based Ethnomathematics Instructional Content Repository is an online system that can only be assessed by respondents who have used the system and have been duly validated as belonging to the desired category of respondents. The online survey presented the items of WEICRAQ as a single, continuous and non-sectioned questionnaire to avoid fatigue due to section switching. All other metric tools used in measuring the platform's behaviour and key performance indices are also hosted online by the respective service providers.

\section{System Specifications and Implementation}

The Web-based Ethnomathematics Instructional Content Repository is hosted on the Internet under the domain name VillageMath.net, with the full URL being https://villagemath.net. Hosting services is being provided by Smartweb Nigeria Limited. The Repository runs on Linux OS server running with cPanel v80.p (Build 20). The website runs on Apache Version 2.4.39, PHP Version 5.6.40 and MySQL Version 5.7.26. 
The Web-based Ethnomathematics Instructional Content Repository is managed through WordPress. WordPress (WordPress.org) is a free and open-source content management system (CMS) based on PHP \& MySQL. PHP is a server-side scripting language for creating dynamic web pages. When a visitor opens a page built in PHP, the server processes the PHP commands and then sends the results to the visitor's browser. MySQL is an open-source relational database management system (RDBMS) that uses Structured Query Language (SQL), the most popular language for adding, accessing, and processing data in a database. MySQL is a big filing cabinet where all the content on a site is stored.

Every time visitors go to https://villagemath.net to interact with ethnomathematics instructional content, they make a request that is sent to a host server. The PHP programming language receives that request, makes a call to the MySQL database, obtains the requested information from the database, and then presents the requested information to the visitors through their web browsers.

Features of WordPress include a plugin architecture and a template system. It is most associated with blogging but supports other types of web content including more traditional mailing lists and forums, media galleries, and online stores. The choice of WordPress 5.4 is based on its flexibility, ease of use, outstanding performance statistics as the most popular website management system and in being used by 60 million websites, including 34\% of the top 10 million websites (BuiltWith, 2019; Colao, 2012; Leibowitz, 2015; W3Tech, 2019).

To function, WordPress has to be installed on a web server, either part of an Internet hosting service like WordPress.com or a computer running the software package WordPress.org in order to serve as a network host in its own right. A local computer may be used for singleuser testing and learning purposes. WordPress has a web template system using a template processor. Its architecture is a front controller, routing all requests for non-static URLs to a single PHP file which parses the URL and identifies the target page (Hayes, 2014). This allows support for more human-readable permalinks.

WordPress users may install and switch among different themes. Themes allow users to change the look and functionality of a WordPress website without altering the core code or site content (WordPress, 2019). Every WordPress website requires at least one theme to be present and every theme should be designed using WordPress standards with structured PHP, valid HTML (HyperText Markup Language), and Cascading Style Sheets (CSS). Themes may be directly installed using the WordPress "Appearance" administration tool in the dashboard, or theme folders may be copied directly into the themes directory, for example via FTP. The PHP, HTML and CSS found in themes can be directly modified to alter theme behavior, or a theme can be a "child" theme which inherits settings from another theme and selectively overrides features.

WordPress' plugin architecture allows users to extend the features and functionality of a website or blog. Each plugin offers custom functions and features enabling users to tailor their sites to their specific needs. These customizations range from search engine optimization, client portals used to display private information to logged in users, and content management systems, to content displaying features, such as the addition of widgets and navigation bars.

WordPress also features integrated link management; a search engine-friendly, clean permalink structure; the ability to assign multiple categories to posts; and support for tagging of posts. Automatic filters are also included, providing standardized formatting and styling of text in posts. WordPress also supports the Trackback and Pingback standards for displaying links to other sites that have themselves linked to a post or an article. WordPress posts can be edited in HTML, using the visual editor, or using one of a number of plugins that allow for a variety of customized editing features.

\section{Method of Data Analysis}

Data collected was analyzed using both descriptive and inferential statistics. Research question one was answered using values and charts provided by the Content Managing System adopted by the Web-based Ethnomathematics Instructional Content Repository. Specifically, common web metrics tracked by WP Statistics include hit statistics, search engine referrals, browsers, traffic source and top referring sites, and devices. Hit statistics accounts for the number of visits and unique visitors, with the ratio of the two providing a metric value for average number of pages a visitor views on the villagemath. net platform. In WordPress, the period of time during which requests from the same uniquely identified client is considered a unique visit is 1800 seconds.

Research question two was answered by values and charts provided by third-party website performance measuring services such as Pingdom Tools, Google PageSpeed Insights, GTmetrix and WebPageTest. The KPIs that are of utmost importance to this study are the load time (speed or response time) and size. Speed Index is a page load performance metric that shows how quickly the contents of a page are visibly populated. The lower the score, the better. Similarly, size refers to the overall weight in megabytes (MB) of the contents of a website. The lower the size, the better. The industry standard loading time presently stands at 8.66 seconds while the industry standard page size is $1.88 \mathrm{MB}$, although recommended targets are 3 seconds and $500 \mathrm{~KB}$ respectively (MachMetrics, 2018). Other KPIs measured are first contentful paint, time to interactive, first meaningful paint, and last painted hero. First contentful paint marks the time at which the first text or image is painted. Time to interactive is the amount of time it takes for the web page to become fully interactive. First meaningful paint measures when the primary content of a page is visible. The last painted hero indicates the time it takes for the last important element on the page to be loaded.

Research questions three to seven were answered by the WEICRAQ and analyzed using mean and standard deviation. The research hypotheses were tested at 0.05 level of significance using the t-test. The t-test was used because it provides an appropriate measure of the statistically significant difference between two independent random samples from normal populations whose variances are not necessarily equal. Pre-service and in-service mathematics teachers constitute the two independent samples in this study.

\section{RESULTS}

The presentation of data analysis and interpretation of results for this study was done according to the research questions and followed by related hypothesis. 
Table 1. Hits Statistics

\begin{tabular}{|c|c|c|c|}
\hline Month & Visits & Visitors & APPV $^{\star}$ \\
\hline June 2019 & 5269 & 1316 & 4.00 \\
\hline July 2019 & 22,762 & 3437 & 6.62 \\
\hline August 2019 & 4690 & 1597 & 2.94 \\
\hline September 2019 & 10353 & 2852 & 3.63 \\
\hline October 2019 & 20400 & 4867 & 4.19 \\
\hline November 2019 & 15845 & 4289 & 3.69 \\
\hline December 2019 & 13591 & 3818 & 3.56 \\
\hline January 2020 & 14886 & 4231 & 3.52 \\
\hline February 2020 & 14669 & 4275 & 3.43 \\
\hline March 2020 & 16575 & 5600 & 2.96 \\
\hline Total & 139246 & 36359 & 3.83 \\
\hline
\end{tabular}

${ }^{\star}$ APPV: Average Pages Per Visitor

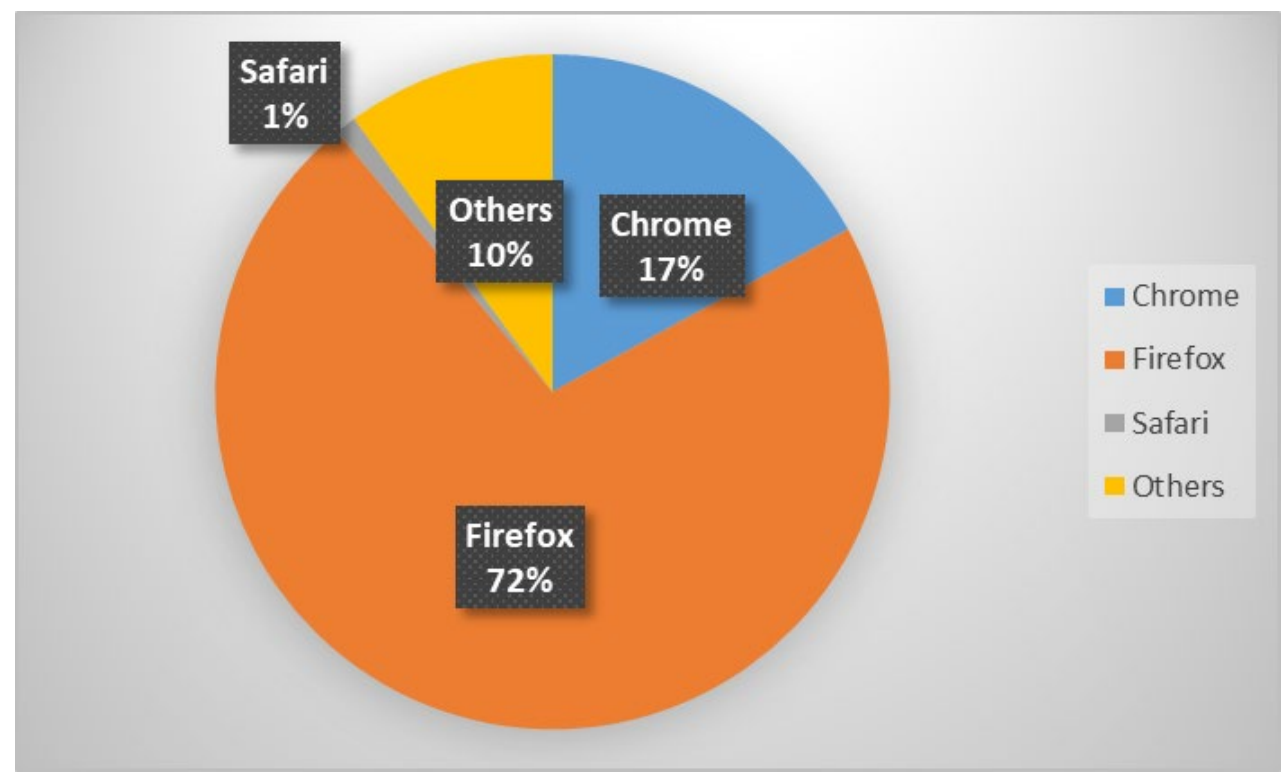

Figure 2. Browser Statistics

\section{Research Question One}

What are the patterns of common web metrics of the web-based ethnomathematics instructional content repository?

The results in Table 1 indicate that over the ten-month period a total number of 36359 unique users visited the Web-based Ethnomathematics Instructional Content Repository at https://villagemath.net for a total of 139246 unique visits. This translates to an average of 3.83 pages per visitor. The implication of this APPV is that on the average, each visitor (user) to the platform is engaged enough by the content to navigate to at least four different web pages, thereby having a high level of interaction with the Web-based Ethnomathematics Instructional Content Repository.

The data presented in Figure 2 indicate that Firefox is the web browser most widely used by users to visit the Web-based Ethnomathematics Instructional Content Repository at https://villagemath.net. Google Chrome browser came second, being used by $17 \%$ of visitors to access the platform.

The pie chart in Figure 3 shows that $75 \%$ of visitors to the Web-based Ethnomathematics Instructional Content Repository at https://villagemath.net visit via mobile devices, particularly smartphones. This is followed by desktop users (19\%) using personal computers and laptops. Tablet users account for only $6 \%$ traffic to the platform.

Traffic to the Web-based Ethnomathematics Instructional Content Repository at https://villagemath.net_came through direct visit $(52 \%)$ by users typing the platform's URL in their web browsers. Those who follow links shared on various social media platforms constitute $47 \%$ of the traffic, while search engines account for only $1 \%$ of the traffic. 


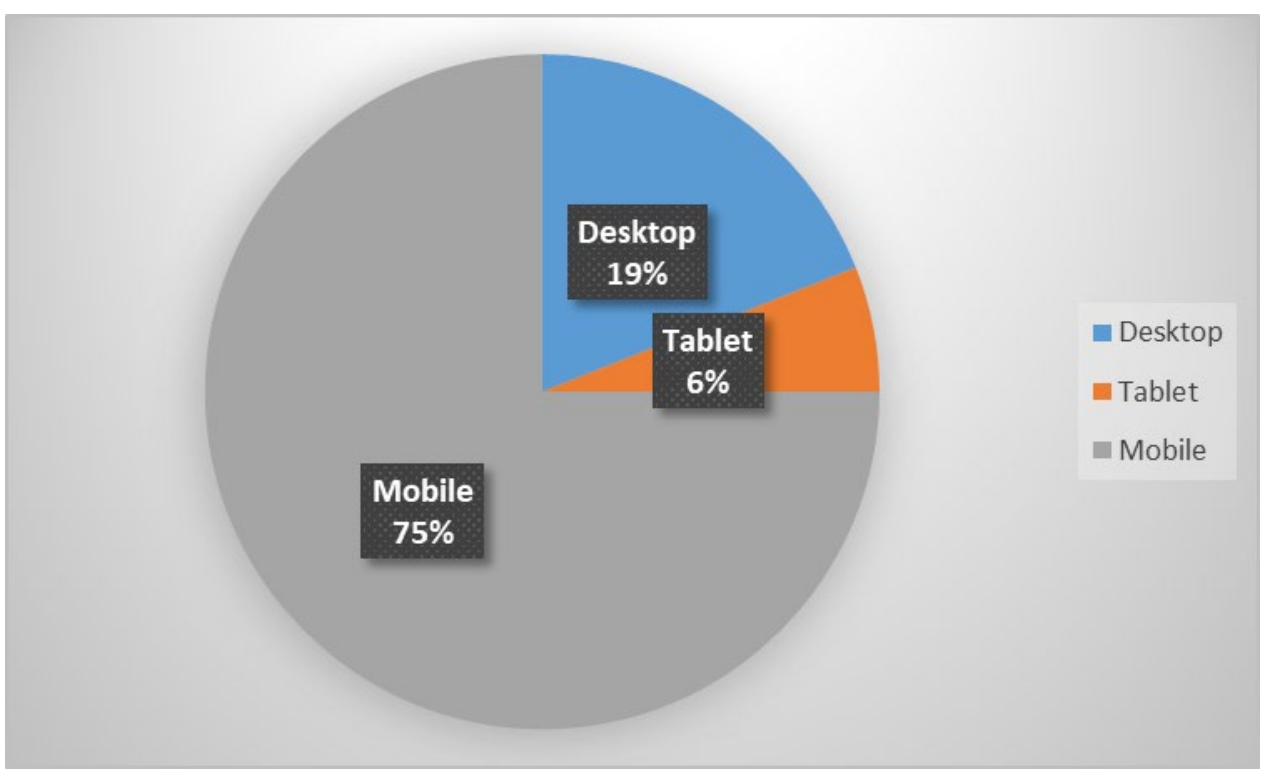

Figure 3. Devices

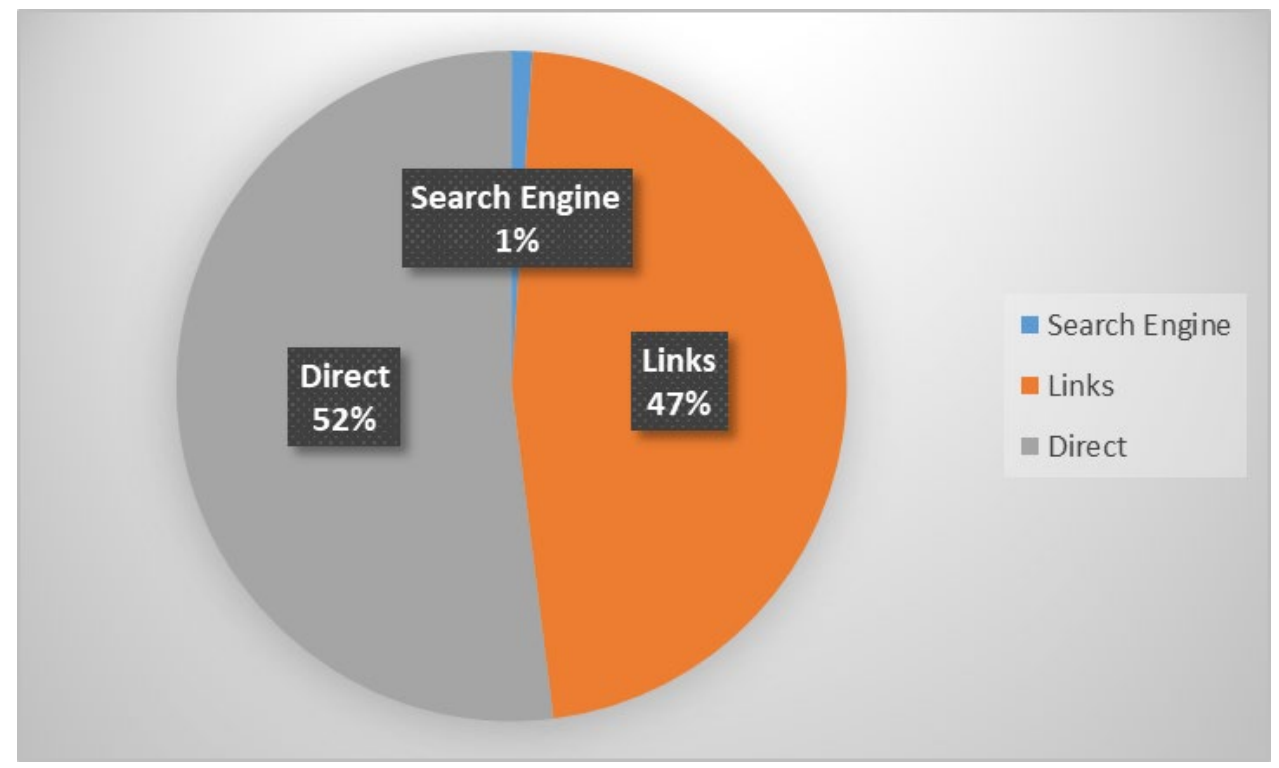

Figure 4. Traffic Source

Table 2. Search Engine Ranking

\begin{tabular}{ccc}
\hline Search Engine & Ranking \\
\hline Google & 1 \\
\hline Bing & 2 \\
\hline Yahoo! & 3 \\
\hline DuckDuckGo & 4 \\
\hline Yandex & 5 & \\
\hline Ask.com & 6 \\
\hline
\end{tabular}

The results in Table 2 indicate that Google tops the search engine traffic to the Web-based Ethnomathematics Instructional Content Repository at https://villagemath.net. The print-out of the top search words tracked by WP Statistics indicates that commonly searched terms leading visitors from search engines to the platform include "how many mudus make one basket", "village math", "mathematics is all around us", "ethnomathematics in Nigeria", "how many cups is one custard rubber", "counting number in tiv language", "why did tiv borrow words from English", "ethnomathematics article", "research articles on ethnomathematics and geometry", "Christmas gifts", "measuring bowl", "village games", "orokam traditional history", and "measurement of grains in northern Nigeria." The report on topvisiting countries indicates that users from a total of 126 countries have visited the Web-based Ethnomathematics Instructional Content Repository at https://villagemath.net.

The data in Table 3 indicates that the post on "Mudu as a Market Measure" is the most visited ethnomathematics instructional content on the VillageMath platform. This corroborates the distribution of search words redirecting traffic to https://villagemath.net from major search engines across the world. 
Table 3. Top Visited Pages

\begin{tabular}{cc}
\hline Rank & Post (Page) \\
\hline 1. & "Mudu" as a Market Measure \\
\hline 2. & The Traditional I'tche (Mancala) Board Game of the Orokam People \\
\hline 3. & The First Tiv Computing System* \\
\hline 4. & Olo Igbi: The Spinning Snail Shell Game \\
\hline 5. & VillageMath Survey \\
\hline 6. & Tiv as a Language for Mathematics Instruction \\
\hline 7. & Story Telling \\
\hline 8. & \\
\hline 9. & About Us \\
\hline 10. &
\end{tabular}

Table 4. Key Performance Indices from Pingdom Tools

\begin{tabular}{|c|c|c|c|}
\hline Test Server Location & Performance Grade & Load Time & Page Size \\
\hline Asia - Japan - Tokyo & $67(\mathrm{D})$ & $4.41 \mathrm{~s}$ & $2.4 \mathrm{MB}$ \\
\hline Europe - Germany - Frankfurt & $67(\mathrm{D})$ & $2.50 \mathrm{~s}$ & $2.4 \mathrm{MB}$ \\
\hline Europe - United Kingdom - London & $68(\mathrm{D})$ & $2.80 \mathrm{~s}$ & $2.4 \mathrm{MB}$ \\
\hline North America - USA - Washington DC & $67(\mathrm{D})$ & $1.19 \mathrm{~s}$ & $2.4 \mathrm{MB}$ \\
\hline North America - USA - San Francisco & $68(D)$ & $2.19 \mathrm{~s}$ & $2.4 \mathrm{MB}$ \\
\hline Pacific - Australia - Sydney & 67 (D) & $5.14 \mathrm{~s}$ & $2.4 \mathrm{MB}$ \\
\hline South America - Brazil - Sao Paulo & $67(\mathrm{D})$ & $3.74 \mathrm{~s}$ & $2.4 \mathrm{MB}$ \\
\hline Mean & 67.29 (D) & $3.14 \mathrm{~s}$ & 2.4MB \\
\hline
\end{tabular}

Table 5. Key Performance Indicators from Google PageSpeed Insights

\begin{tabular}{cccccc}
\hline Platform (View Type) & Overall Score & First Contentful Paint & Speed Index & Time to Interactive & First Meaningful Paint \\
\hline Mobile & 17 & $6.9 \mathrm{~s}$ & $8.3 \mathrm{~s}$ & $11.7 \mathrm{~s}$ & $7.8 \mathrm{~s}$ \\
\hline Desktop & 67 & $1.9 \mathrm{~s}$ & $2.3 \mathrm{~s}$ & $2.0 \mathrm{~s}$ & $2.0 \mathrm{~s}$ \\
\hline
\end{tabular}

\section{Research Question Two}

What are the key performance indicators of the web-based ethnomathematics instructional content repository?

The results in Table 4 show that the Web-based Ethnomathematics Instructional Content Repository at https://villagemath.net score a performance grade 67.29 (D) with a mean load time of 3.14 seconds and a page size of 2.4MB. When seen in the light of industry standard loading time of 8.66 seconds, the Web-based Ethnomathematics Instructional Content Repository at https://villagemath.net loads very fast. The page size of $2.4 \mathrm{MB}$ which is slightly heavier than the industry standard page size of $1.88 \mathrm{MB}$ is due to the graphic nature of the resources available on the platform. The page size still translates to a fair performance score and a fast load time because of the highlevel optimization carried out on all graphic contents used on the platform.

The results in Table 5 indicate the KPIs from Google PageSpeed Insights for both mobile and desktop users of the Web-based Ethnomathematics Instructional Content Repository at https://villagemath.net. For the mobile platform, the repository returns a first contentful paint of $6.9 \mathrm{~s}$, an indicator that it takes 6.9 seconds for the first text or image to be painted for a visitor browsing on a smartphone or any mobile device. The results also show that it takes 11.7 seconds for the page to become fully interactive for the mobile user with the primary content of the page becoming visible in 7.8 seconds. The speed index for the mobile view is 8.3 seconds. Corresponding KPIs for a visitor browsing on a desktop platform indicate that the Web-based Ethnomathematics Instructional Content Repository at https://villagemath.net performs better on desktop devices like PCs and Laptops at a speed index of 2.3 seconds. When seen in the light of industry standard loading time of 8.66 seconds, the Web-based Ethnomathematics Instructional Content Repository at https://villagemath.net loads very fast on both mobile and desktop platforms.

The KPIs from GTmetrix shown in Table 6 indicate a mean PageSpeed score of 47\%, a mean fully loaded time of 5.69s and a mean total page size of 2.10 MB for the Web-based Ethnomathematics Instructional Content Repository at https://villagemath.net. The fully loaded time of the ethnomathematics platform beats the GTmetrix average of 6.4 seconds, implying the platform is faster than any average website measured on GTmetrix. Similarly, the platform's total page size is smaller than the GTmetrix average of 3.02 MB, indicating that the content of the repository is lighter and easier to interact with than any average site measured on GTmetrix. However, the PageSpeed score of $47 \%$ is below the GTmetrix average of $73 \%$, pointing to the potential of the website to be faster using better practices and optimization principles. For each test server location, GTmetrix generates a test report which include recommendations for future improvements. Such recommendations include enabling compression, serving scaled images, leveraging browser caching, optimizing images, using efficient content delivery network (CDN), and compressing components. 
Table 6. Key Performance Indices from GTmetrix

\begin{tabular}{|c|c|c|c|}
\hline Test Server Region & PageSpeed Score* & Fully Loaded Time** & Total Page Size ${ }^{\star \star \star}$ \\
\hline Dallas, USA & $47 \%(F)$ & $6.0 \mathrm{~s}$ & $2.10 \mathrm{MB}$ \\
\hline Hong Kong, China & $47 \%(F)$ & $5.8 \mathrm{~s}$ & $2.10 \mathrm{MB}$ \\
\hline London, UK & $47 \%(F)$ & $3.6 \mathrm{~s}$ & $2.10 \mathrm{MB}$ \\
\hline Mumbai, India & $47 \%(F)$ & $4.4 \mathrm{~s}$ & $2.10 \mathrm{MB}$ \\
\hline Sydney, Australia & $47 \%(F)$ & $5.6 \mathrm{~s}$ & $2.10 \mathrm{MB}$ \\
\hline Sao Paulo, Brazil & $47 \%(F)$ & $9.6 \mathrm{~s}$ & $2.10 \mathrm{MB}$ \\
\hline Vancouver, Canada & $47 \%(F)$ & $4.8 \mathrm{~s}$ & $2.10 \mathrm{MB}$ \\
\hline Mean & $47 \%$ (F) & 5.69s & $2.10 \mathrm{MB}$ \\
\hline
\end{tabular}

${ }^{*}$ GTmetrix average PageSpeed Score is $73 \%$;

${ }^{* *}$ GTmetrix average Fully Loaded Time is 6.4s;

${ }^{\star \star \star}$ GTmetrix average Total Page Size is $3.02 \mathrm{MB}$

Table 7. Key Performance Indices from WebPage Test

\begin{tabular}{|c|c|c|c|c|c|c|}
\hline Test Location & $\begin{array}{l}\text { Load } \\
\text { Time }\end{array}$ & $\begin{array}{c}\text { First Contentful } \\
\text { Paint } \\
\end{array}$ & $\begin{array}{l}\text { Speed } \\
\text { Index }\end{array}$ & $\begin{array}{c}\text { Last Painted } \\
\text { Hero }\end{array}$ & $\begin{array}{c}\text { Fully Loaded } \\
\text { Time } \\
\end{array}$ & Bytes In (Size) \\
\hline Dulles, VA (Desktop, Android, iOS) & $4.314 \mathrm{~s}$ & $2.139 \mathrm{~s}$ & $2.489 \mathrm{~s}$ & $3.200 \mathrm{~s}$ & $4.880 \mathrm{~s}$ & $2.13 \mathrm{MB}$ \\
\hline San Francisco, CA (Chrome, Firefox, Opera) & $4.817 \mathrm{~s}$ & $2.521 \mathrm{~s}$ & $2.999 \mathrm{~s}$ & $3.833 \mathrm{~s}$ & $5.012 \mathrm{~s}$ & $2.13 \mathrm{MB}$ \\
\hline Toronto, Canada (Chrome, Firefox, Opera) & $4.380 \mathrm{~s}$ & $2.298 \mathrm{~s}$ & $2.861 \mathrm{~s}$ & $3.600 \mathrm{~s}$ & $4.513 \mathrm{~s}$ & $2.13 \mathrm{MB}$ \\
\hline Buenos Aires, Argentina (Firefox, Chrome) & $3.356 \mathrm{~s}$ & $2.020 \mathrm{~s}$ & $2.231 \mathrm{~s}$ & $2.867 \mathrm{~s}$ & $3.611 \mathrm{~s}$ & $2.14 \mathrm{MB}$ \\
\hline Sao Paulo, Brazil (Chrome, Firefox) & $3.888 \mathrm{~s}$ & $2.643 \mathrm{~s}$ & $2.856 \mathrm{~s}$ & $3.400 \mathrm{~s}$ & $4.529 \mathrm{~s}$ & $2.14 \mathrm{MB}$ \\
\hline Nottingham, East Midlands, UK (Chrome, Firefox, Opera) & $4.906 \mathrm{~s}$ & $2.364 \mathrm{~s}$ & $2.807 \mathrm{~s}$ & $3.400 \mathrm{~s}$ & $5.057 \mathrm{~s}$ & $2.13 \mathrm{MB}$ \\
\hline London, UK, - Atlantic.net (Chrome, Firefox, Opera) & $2.758 \mathrm{~s}$ & $1.787 \mathrm{~s}$ & $1.967 \mathrm{~s}$ & $2.733 \mathrm{~s}$ & $4.785 \mathrm{~s}$ & $2.14 \mathrm{MB}$ \\
\hline Orlando, FL (Chrome, Firefox, Opera) & $2.496 \mathrm{~s}$ & $1.339 \mathrm{~s}$ & $1.839 \mathrm{~s}$ & $2.434 \mathrm{~s}$ & $4.317 \mathrm{~s}$ & $2.14 \mathrm{MB}$ \\
\hline Brussels, BE (Chrome, Firefox, Opera) & $3.659 \mathrm{~s}$ & $2.178 \mathrm{~s}$ & $2.744 \mathrm{~s}$ & $3.900 \mathrm{~s}$ & $3.873 \mathrm{~s}$ & $2.14 \mathrm{MB}$ \\
\hline La Rioja, Spain (Chrome, Firefox, Opera) & $5.672 \mathrm{~s}$ & $2.810 \mathrm{~s}$ & $3.052 \mathrm{~s}$ & $4.300 \mathrm{~s}$ & $5.875 \mathrm{~s}$ & $2.14 \mathrm{MB}$ \\
\hline Strasburg, France (Chrome, Firefox, Opera) & $5.465 \mathrm{~s}$ & $2.760 \mathrm{~s}$ & $3.244 \mathrm{~s}$ & $3.900 \mathrm{~s}$ & $6.700 \mathrm{~s}$ & $2.14 \mathrm{MB}$ \\
\hline Paris, France, - EC2 (Chrome, Firefox) & $2.301 \mathrm{~s}$ & $1.502 \mathrm{~s}$ & $1.669 \mathrm{~s}$ & $2.000 \mathrm{~s}$ & $4.667 \mathrm{~s}$ & $2.14 \mathrm{MB}$ \\
\hline Prague, Czech Republic (Chrome, Calvary, Firefox) & $2.608 \mathrm{~s}$ & $1.500 \mathrm{~s}$ & $1.705 \mathrm{~s}$ & $2.100 \mathrm{~s}$ & $3.226 \mathrm{~s}$ & $2.14 \mathrm{MB}$ \\
\hline Warsaw, Poland (Chrome, Firefox, Opera) & $3.472 \mathrm{~s}$ & $2.160 \mathrm{~s}$ & $2.769 \mathrm{~s}$ & $3.500 \mathrm{~s}$ & $3.745 \mathrm{~s}$ & $2.14 \mathrm{MB}$ \\
\hline Istanbul, Turkey (Chrome, Firefox) & $3.433 \mathrm{~s}$ & $1.913 \mathrm{~s}$ & $2.319 \mathrm{~s}$ & $3.000 \mathrm{~s}$ & $3.707 \mathrm{~s}$ & $2.14 \mathrm{MB}$ \\
\hline Mumbai, India, - EC2 (Chrome, Firefox) & $4.341 \mathrm{~s}$ & $2.452 \mathrm{~s}$ & $2.768 \mathrm{~s}$ & $3.700 \mathrm{~s}$ & $4.555 \mathrm{~s}$ & $2.14 \mathrm{MB}$ \\
\hline Israel (Chrome, Firefox, Opera) & $3.252 \mathrm{~s}$ & $1.997 \mathrm{~s}$ & $2.564 \mathrm{~s}$ & $2.933 \mathrm{~s}$ & $3.435 \mathrm{~s}$ & $2.14 \mathrm{MB}$ \\
\hline Tokyo, Japan, - EC2 (Chrome, Firefox) & $3.769 \mathrm{~s}$ & $2.111 \mathrm{~s}$ & $2.341 \mathrm{~s}$ & $3.300 \mathrm{~s}$ & $5.092 \mathrm{~s}$ & $2.14 \mathrm{MB}$ \\
\hline Singapore, EC2 (Chrome, Firefox) & $5.640 \mathrm{~s}$ & $3.166 \mathrm{~s}$ & $3.324 \mathrm{~s}$ & $4.800 \mathrm{~s}$ & $5.888 \mathrm{~s}$ & $2.14 \mathrm{MB}$ \\
\hline Seoul, Korea, EC2 (Chrome, Firefox) & $4.299 \mathrm{~s}$ & $2.453 \mathrm{~s}$ & $2.762 \mathrm{~s}$ & $3.500 \mathrm{~s}$ & $4.503 \mathrm{~s}$ & $2.14 \mathrm{MB}$ \\
\hline Lincoln, Nebraska (Chrome, Firefox, Opera) & $2.755 \mathrm{~s}$ & $1.613 \mathrm{~s}$ & $1.939 \mathrm{~s}$ & $2.600 \mathrm{~s}$ & $4.127 \mathrm{~s}$ & $2.14 \mathrm{MB}$ \\
\hline Amsterdam, NL, - MeasureWorks (Chrome, Firefox) & $2.224 \mathrm{~s}$ & $1.535 \mathrm{~s}$ & $1.621 \mathrm{~s}$ & $2.000 \mathrm{~s}$ & $4.136 \mathrm{~s}$ & $2.14 \mathrm{MB}$ \\
\hline Frankfurt, Germany, - Dynatrace (Chrome, Firefox) & $2.356 \mathrm{~s}$ & $1.425 \mathrm{~s}$ & $1.689 \mathrm{~s}$ & $2.200 \mathrm{~s}$ & $3.354 \mathrm{~s}$ & $2.14 \mathrm{MB}$ \\
\hline Mean & 3.74s & $2.11 \mathrm{~s}$ & $2.46 \mathrm{~s}$ & $3.16 \mathrm{~s}$ & 4.49s & $2.138 \mathrm{MB}$ \\
\hline
\end{tabular}

The results in Table 7 are the outcome of WebPage Test from 25 different test server locations across the globe. The data indicate that the Web-based Ethnomathematics Instructional Content Repository at https://villagemath.net yields a mean loaded time of 3.74 seconds, a mean first contentful paint of 2.11 seconds, a mean speed index of 2.46 seconds, a mean last painted hero of 3.16 seconds, a mean fully loaded time of $4.49 \mathrm{~s}$, and mean page size of $2.138 \mathrm{MB}$. The mean loaded time indicate that it takes the repository 3.74 seconds to load on any web browser. The first contentful paint score implies it takes the browser 2.11 seconds to render the first piece of DOM (Document Object Model) content after a user navigates to the web page. The mean score for the last painted hero implies that it takes 3.16 seconds for the last important element on the site to be loaded. All these KPIs culminate in a mean speed index of 2.46 seconds, a very high speed when measured against the industry standard speed of 8.66 seconds.

\section{Research Question Three}

To what extent do pre-service and in-service Mathematics teachers in Benue State rate the quality of the web-based ethnomathematics instructional content repository in terms of content?

In Table 8, the result shows that pre-service and in-service mathematics teachers in Benue State rate the Web-based Ethnomathematics Instructional Content Repository high in terms of content, considering the high cluster means of 3.31 for Pre-Service Teachers and 3.35 for In-Service Teachers, which are both above the benchmark of 2.50 . 
Table 8. Mean Scores of Pre-Service and In-Service Mathematics Teachers' Rating of the Web-based Ethnomathematics Instructional Content Repository in terms of Content

\begin{tabular}{|c|c|c|c|c|c|c|c|}
\hline \multirow{2}{*}{ S/NO. } & \multirow{2}{*}{ Item } & \multicolumn{3}{|c|}{ Pre-Service $(\mathrm{N}=\mathbf{2 4 1})$} & \multicolumn{3}{|c|}{ In-Service $(\mathrm{N}=100)$} \\
\hline & & Mean & SD & Remark & Mean & SD & Remark \\
\hline 1 & Information on villagemath.net is current and timely for mathematics teachers. & 3.32 & 0.70 & High & 3.35 & 0.87 & High \\
\hline 2 & Information on villagemath.net is accurate for mathematics teachers. & 3.51 & 0.72 & High & 3.29 & 0.86 & High \\
\hline 3 & Information on villagemath.net is relevant to mathematics teachers. & 3.53 & 0.50 & High & 3.65 & 0.47 & High \\
\hline 4 & Information on the website is rich in detail for mathematics teachers. & 3.47 & 0.55 & High & 3.57 & 0.63 & High \\
\hline 5 & Mathematics teachers' privacy is protected on villagemath.net & 3.31 & 0.75 & High & 3.52 & 0.71 & High \\
\hline $6^{*}$ & The content of the website is not useful to mathematics teachers. & 3.27 & 0.91 & High & 3.03 & 1.13 & High \\
\hline 7 & The content of villagemath.net is complete. & 3.18 & 0.66 & High & 3.39 & 0.79 & High \\
\hline 8 & The content of the website is clear. & 3.49 & 0.55 & High & 3.47 & 0.64 & High \\
\hline 9 & The content of the website is concise. & 3.26 & 0.61 & High & 3.24 & 0.66 & High \\
\hline $10^{*}$ & Mathematics teachers cannot rely on the villagemath.net website. & 2.84 & 0.91 & High & 2.75 & 1.00 & High \\
\hline 11 & The site provides reliable ethnomathematics content. & 3.27 & 0.85 & High & 3.57 & 0.63 & High \\
\hline & Cluster Mean & 3.31 & - & High & 3.35 & - & High \\
\hline
\end{tabular}

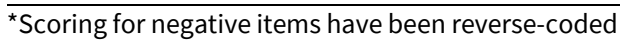

Table 9. Mean Scores of Pre-Service and In-Service Mathematics Teachers' Rating of the Web-based Ethnomathematics Instructional Content Repository in terms of Navigation

\begin{tabular}{|c|c|c|c|c|c|c|c|}
\hline \multirow{2}{*}{ S/NO. } & \multirow{2}{*}{ Item } & \multicolumn{3}{|c|}{ Pre-Service $(\mathrm{N}=\mathbf{2 4 1})$} & \multicolumn{3}{|c|}{ In-Service $(\mathrm{N}=100)$} \\
\hline & & Mean & SD & Remark & Mean & SD & Remark \\
\hline 1 & Web pages on villagemath.net load fast. & 3.35 & 0.78 & High & 3.58 & 0.69 & High \\
\hline 2 & $\begin{array}{l}\text { Mathematics teachers visiting the villagemath.net website are able to obtain the information } \\
\text { they want without any delay. }\end{array}$ & 3.15 & 0.68 & High & 3.41 & 0.77 & High \\
\hline $3^{\star}$ & The website villagemath.net is not available all the time. & 3.29 & 0.88 & High & 2.95 & 1.12 & High \\
\hline 4 & Links on the villagemath.net platform lead to instantaneous information. & 3.28 & 0.66 & High & 3.34 & 0.69 & High \\
\hline $5^{\star}$ & Accessing information on villagemath.net is difficult. & 3.34 & 0.74 & High & 3.02 & 0.95 & High \\
\hline 6 & Information category on the website is simple and straightforward. & 3.53 & 0.62 & High & 3.47 & 0.74 & High \\
\hline 7 & $\begin{array}{l}\text { The website has many interactive service features such as comments, contact, and forum } \\
\text { that can be easily accessed. }\end{array}$ & 3.23 & 0.78 & High & 3.51 & 0.64 & High \\
\hline 8 & The villagemath.net website has adequate search facilities. & 3.32 & 0.71 & High & 3.37 & 0.79 & High \\
\hline 9 & The site exhibits easy orientation for different devices and browsers. & 3.38 & 0.69 & High & 3.24 & 0.69 & High \\
\hline 10 & Learning to operate the website is easy. & 3.71 & 0.45 & High & 3.53 & 0.50 & High \\
\hline 11 & Mathematics teachers are able to find what they need quickly on this website. & 3.32 & 0.67 & High & 3.29 & 0.69 & High \\
\hline $12^{\star}$ & The layout available on villagemath.net makes it difficult to navigate the platform. & 2.90 & 0.77 & High & 3.18 & 0.55 & High \\
\hline 13 & Hyperlinks on the website are valid. & 3.18 & 0.81 & High & 3.57 & 0.49 & High \\
\hline & Cluster Mean & 3.31 & - & High & 3.34 & - & High \\
\hline
\end{tabular}

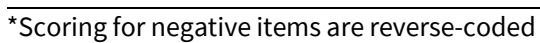

\section{Research Question Four}

To what extent do pre-service and in-service Mathematics teachers in Benue State rate the quality of the web-based ethnomathematics instructional content repository in terms of navigation?

The results in Table 9 indicate that pre-service and in-service mathematics teachers in Benue State rate the Web-based Ethnomathematics Instructional Content Repository high in terms of navigation, considering the high cluster mean of 3.31 and 3.34 for Pre-Service Teachers and In-Service Teachers respectively. Both means are above the benchmark of 2.50.

\section{Research Question Five}

To what extent do pre-service and in-service Mathematics teachers in Benue State rate the quality of the web-based ethnomathematics instructional content repository in terms of structure?

The results shown in Table 10 indicate cluster means of 3.34 (Pre-Service Teachers) and 3.37 (In-Service Teachers) which are higher than the benchmark of 2.50. This implies that pre-service and in-service mathematics teachers in Benue State rate the Web-based Ethnomathematics Instructional Content Repository high in terms of structure. 
Table 10. Mean Scores of Pre-Service and In-Service Mathematics Teachers' Rating of the Web-based Ethnomathematics Instructional Content Repository in terms of Structure

\begin{tabular}{|c|c|c|c|c|c|c|c|}
\hline \multirow{2}{*}{ S/NO. } & \multirow[b]{2}{*}{ Item } & \multicolumn{3}{|c|}{ Pre-Service $(\mathrm{N}=241)$} & \multicolumn{3}{|c|}{ In-Service ( $\mathrm{N}=100)$} \\
\hline & & Mean & SD & Remark & Mean & SD & Remark \\
\hline 1 & Services on villagemath.net is easy to locate. & 3.30 & 0.72 & High & 3.32 & 0.69 & High \\
\hline 2 & The structure of the website shows originality in design. & 3.57 & 0.49 & High & 3.62 & 0.48 & High \\
\hline 3 & The website has a fast loading speed. & 3.46 & 0.52 & High & 3.60 & 0.58 & High \\
\hline $4^{\star}$ & The site is not adaptable to all devices and screens. & 2.75 & 0.95 & High & 2.40 & 1.03 & Low \\
\hline 5 & The villagemath.net website has a functional sitemap. & 3.27 & 0.57 & High & 3.28 & 0.55 & High \\
\hline 6 & The website is compatible with different web browsers. & 3.47 & 0.64 & High & 3.62 & 0.48 & High \\
\hline 7 & The site has a simple background schemes. & 3.41 & 0.64 & High & 3.31 & 0.61 & High \\
\hline 8 & Information structure on villagemath.net reflects order and togetherness of information. & 3.34 & 0.68 & High & 3.29 & 0.71 & High \\
\hline 9 & Visiting the site does not require any specialized software. & 3.47 & 0.62 & High & 3.34 & 0.57 & High \\
\hline 10 & The villagemath.net site is responsive in providing information in real time conditions. & 3.32 & 0.71 & High & 3.54 & 0.64 & High \\
\hline 11 & $\begin{array}{l}\text { Links to share topics from villagemath.net to different social media platforms (such as twitter } \\
\text { and facebook) makes the site desirable. }\end{array}$ & 3.39 & 0.67 & High & 3.34 & 0.62 & High \\
\hline 12 & $\begin{array}{l}\text { The availability of discussion forums on villagemath.net makes the platform professional for } \\
\text { mathematics teachers. }\end{array}$ & 3.42 & 0.60 & High & 3.65 & 0.47 & High \\
\hline 13 & $\begin{array}{l}\text { The user authentication feature of villagemath.net provides additional security for } \\
\text { mathematics teachers on the platform. }\end{array}$ & 3.26 & 0.62 & High & 3.52 & 0.71 & High \\
\hline & Cluster Mean & 3.34 & - & High & 3.37 & - & High \\
\hline
\end{tabular}

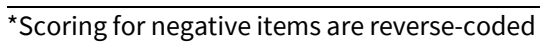

$$
\text { Cluster Mean }
$$

Table 11. Mean Scores of Pre-Service and In-Service Mathematics Teachers' Rating of the Web-based Ethnomathematics Instructional Content Repository in terms of Appearance

\begin{tabular}{|c|c|c|c|c|c|c|c|}
\hline \multirow{2}{*}{ S/NO. } & \multirow{2}{*}{ Item } & \multicolumn{3}{|c|}{ Pre-Service ( $\mathbf{N}=241)$} & \multicolumn{3}{|c|}{ In-Service $(\mathrm{N}=100)$} \\
\hline & & Mean & SD & Remark & Mean & SD & Remark \\
\hline 1 & Web pages on villagemath.net are visually attractive & 3.34 & 0.61 & High & 3.47 & 0.59 & High \\
\hline 2 & The villagemath.net website looks organized. & 3.34 & 0.62 & High & 3.44 & 0.63 & High \\
\hline $3^{\star}$ & The website looks unattractive. & 3.32 & 0.78 & High & 3.14 & 1.02 & High \\
\hline 4 & The website villagemath.net uses fonts properly. & 2.97 & 0.77 & High & 3.05 & 0.81 & High \\
\hline 5 & The website uses colours properly. & 3.07 & 0.59 & High & 3.12 & 0.71 & High \\
\hline 6 & The villagemath.net website uses multimedia features properly. & 2.98 & 0.71 & High & 3.05 & 0.93 & High \\
\hline 7 & The appearance is gratifying with each visit to villagemath.net & 3.11 & 0.65 & High & 3.02 & 0.82 & High \\
\hline $8^{*}$ & The display pages within the website are not easy to read. & 3.10 & 0.93 & High & 2.93 & 0.77 & High \\
\hline 9 & The website labels are easy to understand. & 3.05 & 0.78 & High & 3.49 & 0.64 & High \\
\hline 10 & The website has a clean and simple presentation. & 3.20 & 0.57 & High & 3.62 & 0.63 & High \\
\hline 11 & The combination of image, voice and video on the site are appropriate. & 3.24 & 0.64 & High & 3.48 & 0.50 & High \\
\hline 12 & $\begin{array}{l}\text { The placement of graphics within articles on villagemath.net makes the articles more } \\
\text { attractive for reading }\end{array}$ & 3.43 & 0.64 & High & 3.67 & 0.61 & High \\
\hline & Cluster Mean & 3.18 & - & High & 3.29 & - & High \\
\hline
\end{tabular}

*Scoring for negative items are reverse-coded

\section{Research Question Six}

To what extent do pre-service and in-service Mathematics teachers in Benue State rate the quality of the web-based ethnomathematics instructional content repository in terms of appearance?

In Table 11, the result shows that pre-service and in-service mathematics teachers in Benue State rate the Web-based Ethnomathematics Instructional Content Repository high in terms of appearance, considering the high cluster means of 3.18 and 3.29 which are above the benchmark of 2.50 .

\section{Research Question Seven}

To what extent do pre-service and in-service Mathematics teachers in Benue State rate the quality of the web-based ethnomathematics instructional content repository in terms of uniqueness?

The results in Table 12 indicate that pre-service and in-service mathematics teachers in Benue State rate the Web-based Ethnomathematics Instructional Content Repository high in terms of uniqueness, considering the high cluster means of 3.29 and 3.39 for pre-service and in-service mathematics teachers respectively, which are above the benchmark of 2.50 . 
Table 12. Mean Scores of Pre-Service and In-Service Mathematics Teachers' Rating of the Web-based Ethnomathematics Instructional Content Repository in terms of Uniqueness

\begin{tabular}{|c|c|c|c|c|c|c|c|}
\hline \multirow{2}{*}{ S/NO. } & \multirow{2}{*}{ Item } & \multicolumn{3}{|c|}{ Pre-Service $(\mathrm{N}=\mathbf{2 4 1})$} & \multicolumn{3}{|c|}{ In-Service $(\mathrm{N}=100)$} \\
\hline & & Mean & SD & Remark & Mean & SD & Remark \\
\hline 1 & The website facilitates a unique two-way communication between the visitors and the site. & 3.20 & 0.57 & High & 3.62 & 0.63 & High \\
\hline 2 & $\begin{array}{c}\text { The villagemath.net website can be personalized or customized to meet mathematics } \\
\text { teachers' needs. }\end{array}$ & 3.16 & 0.68 & High & 3.52 & 0.64 & High \\
\hline 3 & The website has a reflective (catchy) name. & 3.33 & 0.76 & High & 3.44 & 0.84 & High \\
\hline 4 & The website made good use of special effects. & 3.27 & 0.63 & High & 3.39 & 0.70 & High \\
\hline 5 & $\begin{array}{l}\text { The information on villagemath.net is pretty much what every teacher needs to carry out my } \\
\text { mathematics teaching tasks. }\end{array}$ & 3.40 & 0.55 & High & 3.32 & 0.61 & High \\
\hline 6 & The website is innovative. & 3.40 & 0.55 & High & 3.48 & 0.64 & High \\
\hline $7^{\star}$ & The ideas expressed on villagemath.net are not creative. & 3.27 & 0.77 & High & 3.28 & 0.86 & High \\
\hline 8 & The website has embedded sociable features. & 3.16 & 0.58 & High & 3.02 & 0.53 & High \\
\hline 9 & The website reflects originality of provided information. & 3.27 & 0.70 & High & 3.46 & 0.64 & High \\
\hline 10 & $\begin{array}{l}\text { The type of information available from the website makes villagemath.net peculiar for } \\
\text { mathematics teachers. }\end{array}$ & 3.37 & 0.66 & High & 3.49 & 0.71 & High \\
\hline $11^{*}$ & The villagemath.net platform is not unique in any way. & 3.20 & 0.75 & High & 3.24 & 0.85 & High \\
\hline 12 & The website is special in encouraging cultural values. & 3.51 & 0.56 & High & 3.36 & 0.80 & High \\
\hline 13 & The villagemath.net platform is unique in providing all resources in downloadable formats & 3.23 & 0.72 & High & 3.47 & 0.78 & High \\
\hline & Cluster Mean & 3.29 & - & High & 3.39 & - & High \\
\hline
\end{tabular}

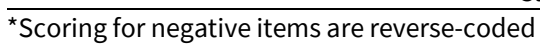

$$
\text { Cluster Mean }
$$

Table 13. t-Test Analysis of Pre-Service and In-Service Mathematics Teachers' Rating of the Web-based Ethnomathematics Instructional Content Repository in terms of Content

\begin{tabular}{|c|c|c|c|c|c|c|c|}
\hline Mathematics Teachers & $\mathbf{N}$ & Mean & Variance & df & t-cal & t-crit & p-value \\
\hline Pre-Service & 241 & 3.31 & 0.146 & \multirow{2}{*}{339} & \multirow{2}{*}{0.728} & \multirow{2}{*}{1.967} & \multirow{2}{*}{$0.467^{\star}$} \\
\hline In-Service & 100 & 3.35 & 0.195 & & & & \\
\hline
\end{tabular}

${ }^{\star}$ Not significant at $\alpha=0.05$

Table 14. t-Test Analysis of Pre-Service and In-Service Mathematics Teachers' Rating of the Web-based Ethnomathematics Instructional Content Repository in terms of Navigation

\begin{tabular}{|c|c|c|c|c|c|c|c|}
\hline Mathematics Teachers & $\mathbf{N}$ & Mean & Variance & df & t-cal & t-crit & p-value \\
\hline Pre-Service & 241 & 3.31 & 0.216 & \multirow{2}{*}{339} & \multirow{2}{*}{0.650} & \multirow{2}{*}{1.967} & \multirow{2}{*}{$0.516^{\star}$} \\
\hline In-Service & 100 & 3.34 & 0.218 & & & & \\
\hline Total & 341 & & & & & & \\
\hline
\end{tabular}

${ }^{\star}$ Not significant at $\alpha=0.05$

\section{Research Hypothesis One}

There is no significant difference in the mean ratings of pre-service Mathematics teachers and in-service Mathematics in Benue State on the quality of the web-based ethnomathematics instructional content repository in terms of content.

Table 13 shows that the $p$-value of 0.467 affirms that there is no significant difference in the mean ratings of pre-service Mathematics teachers and in-service Mathematics teachers in Benue State on the quality of the Web-based Ethnomathematics Instructional Content Repository in terms of content, hence the null hypothesis cannot be rejected at 0.05 level of significance. This is because the $p$-value of 0.467 is greater than the 0.05 level of significance. Also, since the t-calculated value of 0.728 is less than the t-critical value of 1.967 , the null hypothesis cannot be rejected. Eyeballing the means of WEICRAQ scores for the cluster of items on content quality indicate that both pre-service mathematics teachers (3.31) and in-service mathematics teachers (3.35) unanimously rated the Web-based Ethnomathematics Instructional Content Repository high in terms of content.

\section{Research Hypothesis Two}

There is no significant difference in the mean ratings of pre-service Mathematics teachers and in-service Mathematics in Benue State on the quality of the web-based ethnomathematics instructional content repository in terms of navigation.

The results in Table 14 indicate that since the p-value of 0.516 is greater than the stated level of significance of 0.05 , the null hypothesis cannot be rejected. Likewise, because the t-calculated value of 0.650 is less than the t-critical value of 1.967 , the null hypothesis cannot be rejected. This implies that there is no significant difference in the mean ratings of pre-service Mathematics teachers and in-service Mathematics in Benue State on the quality of the Web-based Ethnomathematics Instructional Content Repository in terms of navigation. This result indicates that both categories of mathematics teachers unanimously rated the Web-based Ethnomathematics Instructional Content Repository high in terms of navigation. 
Table 15. t-Test Analysis of Pre-Service and In-Service Mathematics Teachers' Rating of the Web-based Ethnomathematics Instructional Content Repository in terms of Structure

\begin{tabular}{|c|c|c|c|c|c|c|c|}
\hline Mathematics Teachers & $\mathbf{N}$ & Mean & Variance & df & t-cal & t-crit & p-value \\
\hline Pre-Service & 241 & 3.34 & 0.183 & \multirow{2}{*}{339} & \multirow{2}{*}{0.620} & \multirow{2}{*}{1.967} & \multirow{2}{*}{$0.535^{\star}$} \\
\hline In-Service & 100 & 3.37 & 0.187 & & & & \\
\hline Total & 341 & & & & & & \\
\hline
\end{tabular}

${ }^{\star}$ Not significant at $\alpha=0.05$

Table 16. t-Test Analysis of Pre-Service and In-Service Mathematics Teachers' Rating of the Web-based Ethnomathematics Instructional Content Repository in terms of Appearance

\begin{tabular}{|c|c|c|c|c|c|c|c|}
\hline Mathematics Teachers & $\mathbf{N}$ & Mean & Variance & df & t-cal & t-crit & p-value \\
\hline Pre-Service & 241 & 3.18 & 0.251 & \multirow{2}{*}{339} & \multirow{2}{*}{1.845} & \multirow{2}{*}{1.967} & \multirow{2}{*}{$0.066^{\star}$} \\
\hline In-Service & 100 & 3.29 & 0.276 & & & & \\
\hline Total & 341 & & & & & & \\
\hline
\end{tabular}

${ }^{\star}$ Not significant at $\alpha=0.05$

Table 17. t-Test Analysis of Pre-Service and In-Service Mathematics Teachers' Rating of the Web-based Ethnomathematics Instructional Content Repository in terms of Uniqueness

\begin{tabular}{|c|c|c|c|c|c|c|c|}
\hline Mathematics Teachers & $\mathbf{N}$ & Mean & Variance & df & t-cal & t-crit & p-value \\
\hline Pre-Service & 241 & 3.29 & 0.201 & \multirow{2}{*}{339} & \multirow{2}{*}{1.911} & \multirow{2}{*}{1.967} & \multirow{2}{*}{$0.057^{\star}$} \\
\hline In-Service & 100 & 3.39 & 0.199 & & & & \\
\hline Total & 341 & & & & & & \\
\hline
\end{tabular}

${ }^{\star}$ Not significant at $\alpha=0.05$

\section{Research Hypothesis Three}

There is no significant difference in the mean ratings of pre-service Mathematics teachers and in-service Mathematics teachers in Benue State on the quality of the web-based ethnomathematics instructional content repository in terms of structure.

The outcome of the t-test analysis in Table 15 indicates that because the $t$-calculated value of 0.620 is less than the $t$-critical value of 1.967 , the null hypothesis cannot be rejected. Additionally, since the p-value of 0.535 is greater than the stated level of significance of 0.05 , the null hypothesis cannot be rejected. This implies that there is no significant difference in the mean ratings of pre-service Mathematics teachers and in-service Mathematics in Benue State on the quality of the Web-based Ethnomathematics Instructional Content Repository in terms of structure. This result indicates that both categories of mathematics teachers unanimously rated the Web-based Ethnomathematics Instructional Content Repository high in terms of structure.

\section{Research Hypothesis Four}

There is no significant difference in the mean ratings of pre-service Mathematics teachers and in-service Mathematics teachers in Benue State on the quality of the web-based ethnomathematics instructional content repository in terms of appearance.

The results in Table 16 indicate that the t-calculated value of 1.845 is less than the t-critical value of 1.967, hence the null hypothesis cannot be rejected. Similarly, since the p-value of 0.066 is greater than the stated level of significance of 0.05 , the null hypothesis cannot be rejected. This implies that there is no significant difference in the mean ratings of pre-service Mathematics teachers and in-service Mathematics in Benue State on the quality of the Web-based Ethnomathematics Instructional Content Repository in terms of appearance. This result indicates that both categories of mathematics teachers unanimously rated the Web-based Ethnomathematics Instructional Content Repository high in terms of appearance.

\section{Research Hypothesis Five}

There is no significant difference in the mean ratings of pre-service Mathematics teachers and in-service Mathematics teachers in Benue State on the quality of the web-based ethnomathematics instructional content repository in terms of uniqueness.

The outcome of the t-test analysis in Table 17 indicates that because the t-calculated value of 1.911 is less than the $t$-critical value of 1.967 , the null hypothesis cannot be rejected. Additionally, since the p-value of 0.057 is greater than the stated level of significance of 0.05 , the null hypothesis cannot be rejected. This implies that there is no significant difference in the mean ratings of pre-service Mathematics teachers and in-service Mathematics in Benue State on the quality of the Web-based Ethnomathematics Instructional Content Repository in terms of uniqueness. This result indicates that both categories of mathematics teachers unanimously rated the Web-based Ethnomathematics Instructional Content Repository high in terms of uniqueness.

\section{DISCUSSION}

\section{Pattern of Common Web Metrics of the Web-based Ethnomathematics Instructional Content Repository}

The results displayed in Table 1 indicated an average of 3.83 pages per visitor for the Web-based Ethnomathematics Instructional Content Repository. This high APPV implies that on the average, each visitor (user) to the platform is engaged enough by the content to 
navigate to at least four different web pages, thereby having a high level of interaction with the Repository. These users access the instructional platform via browsers like Firefox, Chrome, Safari and Opera, using largely mobile smartphones (75\%), desktop devices (19\%) such as PCs and laptops and tablets (6\%). Similarly, traffic to the Web-based Ethnomathematics Instructional Content Repository at https://villagemath.net_came through direct visit (52\%) by users typing the platform's URL in their web browsers and users who followed links (47\%) shared on various social media platforms with search engines accounting for only $1 \%$ of the traffic. These web metrics attest to the modern trend of Internet usage across the globe which points to increasing mobile penetration (Bahia \& Suardi, 2019; lji \& Abah, 2019; Kemp, 2019). The active engagement revealed by the platform's high average pages per visitor gives the designed tool the potential to build a deeper understanding of mathematics content among users (Abah, Anyagh, \& Age, 2017; Agbo-Egwu, Abah, \& Abakpa, 2018).

The wide usefulness of the Web-based Ethnomathematics Instructional Content Repository is seen in the all-time search engine referrals. The commonly searched terms leading visitors from search engines to the platform ranges from "how many mudus make one basket", "village math", "mathematics is all around us", "ethnomathematics in Nigeria", "how many cups is one custard rubber", "counting number in tiv language", "why did tiv borrow words from English", "ethnomathematics article", "research articles on ethnomathematics and geometry", "Christmas gifts", "measuring bowl”, "village games", "orokam traditional history", to "measurement of grains in northern Nigeria" as indicated in the print-out of top search words, top referring sites, and top referring countries. Considering that users from a total of 126 countries have visited the Web-based Ethnomathematics Instructional Content Repository at https://villagemath.net, it can be inferred that interest in ethnomathematics instructional resources is universal (Kanaiaupuni, 2007). As a learning environment grounded in culture-based mathematics, the Web-based Ethnomathematics Instructional Content Repository stand to motivate students' interest in learning Mathematics and enhance their initiatives in the classroom (Garmpis, 2011; Jung, Jun, \& Gruenwald, 2001; Kartam \& Al-Rashaid, 2002; Ofoegbu et al., 2014; Yao, 2016).

\section{Key Performance Indicators of the Web-based Ethnomathematics Instructional Content Repository}

The results in Table 4 show the key performance indicators (KPIs) of Web-based Ethnomathematics Instructional Content Repository at https://villagemath.net based on Pingdom tools. When seen in the light of industry standards, the page size (2.4 MB) and load time (3.14 seconds) translates to a high performance of the repository because of the high-level optimization carried out on all graphic contents used on the platform. Similar findings in Table 5 from Google PageSpeed Insights for users of the platform indicate that the repository performs at a speed index of 2.3 seconds. When weighed against the industry standard loading time of 8.66 seconds, the platform loads very fast for both mobile and desktop users. The KPIs from GTmetrix shown in Table 6 indicate a mean fully loaded time of 5.69s and a mean total page size of 2.10 MB for the Web-based Ethnomathematics Instructional Content Repository at https://villagemath.net which beat the GTmetrix average of 6.4 seconds and $3.02 \mathrm{MB}$ respectively. This implies that the platform is faster, lighter and easier to interact with than any average site measured on GTmetrix. The moderate GTmetrix PageSpeed score of $47 \%$ points to the potential of the website to be faster using better practices and optimization principles. In line with accepted guidelines, these KPIs use dynamic numbers to arrive at an in-depth picture of user behaviour on the platform, allowing the Web-based Ethnomathematics Instructional Content Repository to align goals, identify areas of improvement, test new functionalities, and ultimately make the desired impact on users (Booth \& Jansen, 2010). Accordingly, for each test server location, GTmetrix generates a test report which include recommendations for future improvements. Such recommendations include enabling compression, serving scaled images, leveraging browser caching, optimizing images, using efficient content delivery network (CDN), and compressing components.

The analysis of results in Table 7 indicates that the Web-based Ethnomathematics Instructional Content Repository at https://villagemath.net yields a mean loaded time of 3.74 seconds, a mean first contentful paint of 2.11 seconds, a mean speed index of 2.46 seconds, a mean last painted hero of 3.16 seconds, a mean fully loaded time of $4.49 \mathrm{~s}$, and mean page size of $2.138 \mathrm{MB}$. These KPIs mean that it takes the repository 3.74 seconds to load, 2.11 seconds to render the first piece of DOM content after a user navigates to the web page, and 3.16 seconds for the last important element on the site to be loaded. All these KPIs culminate in a mean speed index of 2.46 seconds, a very high speed when measured against the industry standard speed of 8.66 seconds. These web analytic metrics affects number of visits and visitors, and visit duration. In reality, sometimes it could just be a webpage element that the browser has problem loading. As Horton (2019) observes, if the user gets frustrated and leaves because that last element affects functionality and their ability to do anything or even read text, that ultimately affects the sites bounce rate, time on site and user satisfaction.

\section{Quality of the Web-based Ethnomathematics Instructional Content Repository in terms of Content}

The results in Table 8 show that pre-service and in-service mathematics teachers in Benue State rate the Web-based Ethnomathematics Instructional Content Repository high in terms of content. Content implies quality, completeness, degree of specialization or generalization, responsiveness, trustfulness, and reliability of information conveyed on the platform (Gauch \& Xand, 2000). As seen in Table 8, the respondents of this study agree that the content of the platform is current, timely, clear, concise, secure, reliable and relevant for mathematics teachers in Benue State, Nigeria. Basically, the content of the repository includes instructional articles, culture-based lesson plans, instructional procedures for adapting cultural artefacts, mathematics community forums, and indigenous mathematical games. By rating the platform high, pre-service and in-service mathematics teachers in Benue State have attested to the repository's contextualization of Mathematics as a school subject. This finding particularly agrees with Ebby et al. (2011) in the use of locally relevant contexts-situations and phenomena to drive personal meaning for both learners and teachers for whom the mathematics curriculum was designed. The content available on the Web-based Ethnomathematics Instructional Content Repository affords them the opportunity to use what they already know to figure new things out (Epper \& Baker, 2009). The outcomes in Table 8 indicate that the designed e-learning tool possesses the characteristics that reflect the culture of its originators and users, and underscore the pedagogies that can gratify their cultural expectations and values (Masoumi \& Lindstrom, 2009; Mondi, Woods \& Rafi, 2007). The quality of the content on the platform affirms that out of school practices are dynamic in nature and that ability to learn Mathematics increases when the students are taught skills that are useful for daily functioning in the home, the workplace, and the community 
(Fantinato \& Vandendriessche, 2018; Neel, 2010). These outcomes are an indication that the Web-based Ethnomathematics Instructional Content Repository is an indispensable teacher-companion for horizontal mathematization in line with the theory of Realistic Mathematics Education (Freudenthal, 1991).

\section{Quality of the Web-based Ethnomathematics Instructional Content Repository in terms of Navigation}

The analysis results in Table 9 indicate that pre-service and in-service mathematics teachers in Benue State rate the Web-based Ethnomathematics Instructional Content Repository high in terms of navigation. Navigation of web-based resources reflects the support provided to users when moving in and around the platform (Moustakis et al., 2004). High quality of navigation implies fast loading web pages, responsive links, adaptability to different devices and browsers, adequate search facilities, and interactive layout. These features are fine-tuned during the enactment phase of the platform's design in line with the tenets of the Integrative Learning design Framework (Bannan-Ritland, 2003). The combination of web-publishing technologies available on WordPress - the Digital Content Management System used in the design of the repository - ensured a seamless navigational experience for users. The DCMS offers digital capabilities that meet the needs and aspiration of this educational initiative (Kay \& Laplante, 2006). WordPress features integrated link management; a search engine-friendly, clean permalink structure; the ability to assign multiple categories to posts; and support for tagging of posts. Available automatic filters provide standardized formatting and styling of text in posts. WordPress also supports the Trackback and Pingback standards for displaying links to other sites that have themselves linked to a post or an article. These capabilities greatly enhance navigation on the platform. The deployed technologies have afforded the Web-based Ethnomathematics Instructional Content Repository the potential to preserve cultural heritage and collections, popularize fine cultural artefacts, encourage knowledge sharing, invigorate cultural content, and improve literacy and creativity (Hsu, Ke, \& Yang, 2006). Unlike the challenges reported in a similar empirical work by Arroyo, Hornos, and Montes (2007), the high rating given the Web-based Ethnomathematics Instructional Content Repository represents a generational leap in the capability of modern technologies used in the design of this repository. Also, the present design deploys underlying technologies similar to those reported by Charles and Babatunde (2014), but without specific focus on course delivery, and real-time synchronous class activities. In contrast, the Web-based Ethnomathematics Instructional Content Repository is basically a resource hub and not a grading/studying for certification environment. Instructional activities for users, particularly pre-service and inservice mathematics teachers, are designed to be consumed in an asynchronous mode with all necessary provision for feedback and user support as attested to in Table 9. While on the platform, teachers are able to reflect upon their ideas before sharing them as threaded discussions, leading to more reflective responses and in-depth learning.

\section{Quality of the Web-based Ethnomathematics Instructional Content Repository in terms of Structure}

The results shown in Table 10 indicate a cluster mean of 3.35 which is higher than the benchmark of 2.50, implying that pre-service and in-service mathematics teachers in Benue State rate the Web-based Ethnomathematics Instructional Content Repository high in terms of structure. The structure of a website refers to aspects that affect order of presentation, speed and browser compatibility (Moustakis et al., 2004). Pre-service and in-service mathematics teachers affirms that the information structure of the repository reflects order and togetherness of information. Again, this design feature was made possible via WordPress' utilization of themes. Themes use technologies such as PHP, HTML, and CSS to change the functionality of the website without altering the core code or content. The structure of the repository is managed by Kontrast (version 1.1.7). Kontrast is a responsive high-resolution theme for blogs and magazines. Kontrast features unique toggle sidebars that give a great browsing and reading experience on both tablet and mobile. The theme also provides unlimited accent colours, unlimited widget area, two flexible custom widgets, localization support, logo upload, and social links. The use of WordPress themes clearly distinguishes the designed platform from those reported by Grampis (2011), Kartain and Al-Reshaid (2002), and Jung, Jun, and Gruenwald (2001).

More structural features are made possible through WordPress plugins. Each plugin offers custom functions and features enabling the repository to adjust to specific needs. Some of the plugins currently active on the website are All in One WP Security, WPSocialite (for managing the loading process of social sharing links), Super Socializer (a complete solution to provide all the social features like Social Login, Social Commenting, Social Sharing, Social Media follow and more), WP Power Stats (powerful real-time statistics for visitors to the site), Companion Sitemap Generator (easy to use XML and HTML sitemap generator and robot editor), Page Views Count, WP Super Cache (for fast loading of content), and Yoast SEO (a search engine optimization tool). These tools work harmoniously to present a site structure and design that is both robust and attractive, providing the user with adequate social integrative uses and gratification expectancy (Mondi, Woods, \& Rafi, 2007). The structural capabilities of the repository in its use of e-mail, message/discussion board, chat room, announcements, comments and feedback, useful links and resource downloads indicate an extension of extant design practices (Kartain \& Al-Reshaid, 2002). Specifically, the availability of discussion forums on the Web-based Ethnomathematics Instructional Content Repository makes the platform structurally professional for mathematics teachers and educators. This professionalism is further aided by links for sharing topics from the platform to social media platforms such as WhatsApp, Telegram, Facebook, Twitter, and LinkedIn, since teachers and educators can extend their professional points of views to other stakeholders within the mathematics education subsector (Abah, Age, \& Okoronkwo, 2018).

The results in Table 10, when weighed against the outcome in Table 2, holds serious positive implications for the platform's visibility on the Internet. Site structure is a vital aspect of Search Engine Optimization (SEO) strategy. The structure of the website shows search engines which pages of the site are most important. This means the site structure influences which articles will rank the highest as can be seen in the results in Table 3. This finding agrees with Van de Rakt (2018) assertion that site structure implies how the websites content is organized. The Web-based Ethnomathematics Instructional Content Repository consists of content of related topics, presented on posts and pages. The unique of the platforms handles how the content is grouped, linked and presented to the visitor. In this structure, users find their way more easily and search engines can index the platform's URLs. In addition, taxonomies like categories and tags, internal links and navigation toggles available on the platform all redirect traffic to the Web-based Ethnomathematics Instructional Content Repository. 


\section{Quality of the Web-based Ethnomathematics Instructional Content Repository in terms of Appearance}

The result in Table $\mathbf{1 1}$ shows that pre-service and in-service mathematics teachers in Benue State rate the Web-based Ethnomathematics Instructional Content Repository high in terms of appearance. Appearance and multimedia captures aspects that relate to the platform's "look and feel" with special emphasis on state-of-the-art graphics and multimedia artefacts (Lavie \& Tractinsky, 2004; Moustakis et al., 2004). The core users of the platform seek interactive multimedia elements that are used to represent culture-based concepts, abstractions, actions or simulations, metaphors and modifiers. They intend to integrate these learning objects available on the platform into complex arguments, in a creative and innovative fashion, as demanded by their specific learning aims outlined in the mathematics curriculum or being canvassed by the culture-based mathematics paradigm (Mondi, Woods, \& Rafi, 2007). Apart from this cognitive uses and gratification expectancy, pre-service and in-service mathematics teachers also seek affective uses and gratification expectancy in their quest for media experiences that evoke pleasure and emotional engagement and enhance their self-efficacy perception. Additionally, the results in Table 11 alluded to high entertainment uses and gratification expectancy. The appearance quality of the repository adequately meets users' tendency to seek e-learning resources that are fun and exciting. The unique intrinsic properties of the resources available on the ethnomathematics platform appeal to users' imaginations and arouse their emotions, matching the users' idiosyncratic appraisal of these properties (Mondi, Woods, \& Rafi, 2007). The appearance value of the platform lies in the tendency of visitors to use multimedia to escape through attention, engagement, aesthetic enjoyment and tension release. This also meets users' expectation that the Web-based Ethnomathematics Instructional Content Repository afford the entertainment, compelling and engaging lesson contents and tasks in form of visual models, multimedia presentations, simulations and indigenous games.

The development of the Web-based Ethnomathematics Instructional Content Repository gave special attention to site appearance because of its impact on user engagement. The Kontrast theme that controlled much of this appearance was selected after trying several others within the framework of the Cleanroom Software Engineering Model (Miles, Dyer, \& Linger, 1987). The theme creatively optimized the site's appearance as can be gleaned from the outcomes reported in Table $\mathbf{1 1}$ and the high average page per visitor arrived at in Table 1. The strategies resulting in these positive outcomes are evidence-based, building on recommendations such as that of Dahal (2011) which underscore that it takes a very short time for users to form an opinion about a website that determines whether they will stay or leave. It was, thus, essential to make the web design of the instructional platform simple and familiar. Users have expectations of what an educational website should look like. Diverting from those is a risk, no matter how imaginative or striking the design (Laja, 2019).

\section{Quality of the Web-based Ethnomathematics Instructional Content Repository in terms of Uniqueness}

The outcomes in Table 12 show that pre-service and in-service mathematics teachers in Benue State rate the Web-based Ethnomathematics Instructional Content Repository high in terms of uniqueness. A platform's uniqueness refers to users' perception that the website carries something that makes it stand out in a world wide web (WWW) full of websites, thereby inducing a sense of loyalty (Moustakis et al., 2004; Sauro, 2015). From the onset, the designed platform is intended to be a one-stop reservoir of online instructional resources that are tailored to the peculiarities of mathematics education as a field of practice in Benue State, Nigeria. These peculiarities include the need to gather indigenous digital content that are multicultural and to prepare pre-service and in-service mathematics teachers to become innovative mathematics instructors, professionally prepared to communicate mathematics to learners at all levels. The development of the repository is to showcase the beauty of everyday mathematics and draw the attention of all stakeholders to the need to make Mathematics more realistic, with particular reference to the cultural context of the subject in Benue State, Nigeria. The mean ratings in Table 12 attest to the attainment of these peculiarities and uniqueness.

In introducing culture to the nexus of discussions and enactments, and seeking to align mathematics instruction to the cultural contexts of ethnically diverse learners, the Web-based Ethnomathematics Instructional Content Repository challenges the mainstream notions of teaching and learning (Bannan-Ritland, 2003; Masoumi \& Lindstrom, 2011). The platform's focus on cross-cultural design for different indigenous cultures, languages and economic standings ensures usability and user experiences across cultural boundaries (Vanio, Walsh, \& Varsaluoma, 2014). The user-centred design approach adopted on the platform allows content to be personalized or customized to meet mathematics teachers' needs. This outcome disagrees with Katmada, Mavridis, and Tsiastos (2014) whose design effort unveiled usability challenges with assessment outcomes suggesting the missing ethnomathematical dimension. The uniqueness of the instructional platform revealed in the results in Table 12 relates to the high level of user satisfaction and accomplishment of user expectation when interfacing with the platform. Both categories of mathematics teachers have attested to the affective and cognitive royalty of the Web-based Ethnomathematics Instructional Content Repository. The user community have indicated that the innovative approaches deployed in the development of the platform appeal to the constructive and meta-cognitive learning that advocate natural eagerness, self-regulation, goal orientation and purposefulness, all within the framework of personal integrative uses and gratification expectancy (Mondi, Woods, \& Rafi, 2007).

The details in Table 12 show that mathematics teachers acknowledge the importance of culture to the identity of learners and how culture affects the way children think and learn. The platform has successfully reminded teachers to value diversity in the mathematics classroom and to understand how culture should influence how mathematics is used and communicated. The catchy name of the repository, the use of special effects, and the downloadable resources have all been attested to reflect originality. The Web-based Ethnomathematics Instructional Content Repository, thus, offers an important perspective for a dynamic and globalized society that accepts that all peoples and cultures develop unique mathematical methods and explanations that allow them to understand, act and transform their own reality (Rosa \& Shirley, 2016).

\section{Unanimous User Experience on the Web-based Ethnomathematics Instructional Content Repository}

The results of this study have measured several aspects or criteria of quality of web-based application development, aggregated to content, navigation, structure, appearance, and uniqueness. The results in Tables 13 to 17 indicate that there is no significant difference in the mean ratings of pre-service and in-service mathematics teachers on the quality of the Web-based Ethnomathematics Instructional 
Content Repository as both categories of mathematics teachers unanimously rated the platform high in terms of content, navigation, structure, appearance, and uniqueness. The harmony returned by the outcomes of tests of five hypotheses is an affirmation of similar user experience for all visitors and users of designed tool at https://villagemath.net. User experience is basically any interaction a user makes with a product or service (Miller, 2020). User experience focuses on having a deep understanding of users, what they need, what they value, their abilities, and also their limitations. The high level of user experience reported in this study was realized through building easy, efficient, relevant and pleasing experience for the user of the instructional platform. All these were achieved via the rigorous frameworks that guided the design, implementation and assessment of the Web-based Ethnomathematics Instructional Content Repository, specifically the Interative Learning Design Framework (Bannan-Ritland, 2003) and the Cleanroom Software Engineering Model (Miles, Dyer, \& Linger, 1987).

One fundamental theoretical assumption underpinning the development of the Web-based Ethnomathematics Instructional Content Repository is that users of web tools are actively making motivated choices (Mondi, Woods, \& Rafi, 2007). These users' belief and evaluations about the gratifications offered by the instructional platform shaped their specific use of the tool, which in turn influence their intention for further use in educational contexts. The teachers' use of ethnomathematical components from within learners' culture has the potential to augment the learners' learning process, help them better understand mathematics instruction content, raise their motivation and ultimately improve their achievement in Mathematics (Agbo-Egwu, Abah, \& Abah, 2018; Fouze \& Amit, 2018).

The two categories of users considered in this study rated high the performance of the Web-based Ethnomathematics Instructional Content Repository. Their internet skills level in using the platform underscores the fact that pre-service and in-service mathematics teachers in Benue State, Nigeria is increasingly participating in the technological transformation presently driving global mathematics education (lji \& Abah, 2019). The agreement in user experience scores of both classes of users indicates that the innovation is more likely to enjoy continuous adaptation in the mathematics classroom considering the high attainment, intrinsic and utility values of the platform (Wozney, Venkatesh, \& Abrami, 2006). This finding agrees with Santos et al. (2016) whose evaluation of similar student-centered e-learning environment indicated high level of user experience. The high level of user experience equally reported by pre-service and in-service mathematics teachers in this study indicates that the Web-based Ethnomathematics Instructional Content Repository can seamlessly deliver culture-based mathematics instruction, support curricular goals and provide a deeper understanding of mathematics content.

\section{SUMMARY}

This study focused on the development and assessment of a web-based ethnomathematics instructional content repository for preservice and in-service mathematics teachers in Benue State, Nigeria. The study employed a developmental research design in building a practical educational intervention within the framework integrative learning design and cleanroom software engineering to enhance mathematics teachers' deployment of indigenous knowledge systems and give insight into forms of Mathematics used diverse cultural contexts around the Benue Valley. Purposive sampling was used to select 341 pre-service and in-service mathematics teachers who have access to the internet and have used the Web-based Ethnomathematics Instructional Content Repository at https://villagemath.net to access the quality of the platform in terms of content, navigation, structure, appearance, and uniqueness.

The main instrument for the study was the Web-based Ethnomathematics Instructional Content Repository Assessment Questionnaire (WEICRAQ) deployed online via JotForm. Additional data collection on common web metrics and key performance indices (KPIs) was handled using web performance assessment tools such as WP Statistics, Pingdom Tools, Google PageSpeed Insights, GTmetrix and WebPage Test. Data collected was analyzed using both descriptive and inferential statistics.

Analysis of results obtained from the web performance assessment tools indicated that the Web-based Ethnomathematics Instructional Content Repository appeals to a wide range of highly engaged users. Key performance indicators such as speed index, page size, and last painted hero for the Web-based Ethnomathematics Instructional Content Repository affirmed that the platform is robust, elegantly designed and fast. The user experience data obtained via the WEICRAQ showed that pre-service and in-service mathematics teachers in Benue State, Nigeria rated the Web-based Ethnomathematics Instructional Content Repository high in terms of content, navigation, structure, appearance, and uniqueness. Hypotheses testing of respondents' WEICRAQ scores along these quality criteria established that there is no significant difference in the mean ratings of pre-service and in-service mathematics teachers on the quality of the Web-based Ethnomathematics Instructional Content Repository as both categories of mathematics teachers unanimously rated the platform high in terms of content, navigation, structure, appearance, and uniqueness. These findings indicated that the designed innovation has the potential to aid Mathematics teachers in providing the necessary guided-re-invention of the mathematics classroom along the culture-based continuum.

\section{CONCLUSION}

The Web-based Ethnomathematics Instructional Content Repository is designed for the grounding of culture-based mathematics instruction and student learning in the values, norms, crafts, beliefs, practices, experiences and language that derive from existing indigenous knowledge systems. The aim is to aid the mathematics teacher to seamlessly lead students from the world of life to the world of mathematical symbols. The outcomes of this design have sufficiently proved that the instructional platform can provide a real-world interface that will assist students' problem solving, support exploration of mathematical concepts, teach dynamically linked representation of ideas and encourage general metacognitive abilities.

This study has specifically evaluated the quality of the designed educational intervention and has provided a scientific basis for generalizing the reliability of the Web-based Ethnomathematics Instructional Content Repository. In view of the prospects of incremental 
development, the fine-grained measurement process undertaken in this study has substantially improved the predictability of the designed web tool. With user interfaces customized to support different instructional approaches according to user styles and preferences, the repository's cognitive aesthetics design is adequately targeted at influencing end-users communication behavior and emotionally impacting their gratification expectancy. The Mathematics teachers' appreciation of the cognitive aesthetics built around the culture-based content as seen in the results of this study should translate to focused usage, guided discovery, intrinsic gratification and enhanced classroom practice. Pre-service and in-service Mathematics teachers are thus expected to transform the learning objects available on the platform, creatively building on available lesson templates to implement multi-faceted culture-based mathematics education in schools.

The outcomes of this study have demonstrated that culture can indeed become an integral part of every aspect of instructional design, making it important to consider social and cultural peculiarities in planning and delivering mathematics instruction. The Web-based Ethnomathematics Instructional Content Repository has humanized Mathematics for users and provided a reservoir of resources for training students in conceptual understanding, procedural fluency, strategic competence, adaptive reasoning and productive disposition. This study has established that the designed instructional platform is positively situated to mediate for mathematics teachers the process of constructing knowledge, with emphasis on students' hands-on activities and indigenous funds of knowledge.

\section{RECOMMENDATIONS}

The following recommendations are made based on the findings of this study:

i. Students across all levels of education should seek deeper and more enriched learning experience by continuously leveraging on instructional resources available on the Web-based Ethnomathematics Instructional Content Repository to enhance their individualized learning, enrich their cultural rediscovery, and add aesthetic value to their learning of Mathematics as a school subject.

ii. Mathematics teachers, both in-service and pre-service, should continue to use the Web-based Ethnomathematics Instructional Content Repository as a worthy companion tailored to their specific professional needs. The platform holds numerous templates for adaptable classroom activities that teacher can access to drive vital conversations in culture-based Mathematics education. The platform's discussion forum available at https://ngsme.villagemath.net is a network of experts and enthusiasts from all over the globe meant to keep Mathematics teachers abreast of international best practices within the discipline.

iii. Mathematics educators in colleges of education and universities should deploy the Web-based Ethnomathematics Instructional Content Repository as a veritable tool for re-directing narratives across the field of Mathematics Education. Scholars of Mathematics Education from within and outside Nigeria should freely use the platform to communicate their development of state-of-the-art pedagogies for the field.

iv. Non-governmental organizations (NGOS) and government agencies in the educational and cultural sectors should make use of the ethnomathematics platform to drive their initiatives in grassroots development. The Web-based Ethnomathematics Instructional Content Repository is open to NGOs like United Nations Education, Scientific and Cultural Organization (UNESCO), International Cultural Youth Exchange (ICYE), Foundation for African Cultural Heritage (FACH), Tender Arts Nigeria (TAN), and government agencies such as Nigerian Tourism Development Corporation (NTDC) and National Council for Arts and Culture (NCAC) as a channel for posting socio-cultural messages to the dedicated followership of the VillageMath Network. Ethnomathematics research-based organizations within and outside Nigeria can also showcase their indigenous knowledge systems via forums hosted on the Webbased Ethnomathematics Instructional Content Repository.

v. Educational policy makers such as the Nigerian Education Research and Development Council (NERDC) should ride on the popularity of the Web-based Ethnomathematics Instructional Content Repository to spur the inclusion of relevant cultural artefacts and indigenous games in the development of the Mathematics curriculum for Basic and Secondary Education. Other establishments like National Universities Commission (NUC), National Council for Colleges of Education (NCCE) and the Mathematical Association of Nigeria (MAN) should consider the progress tracked by this study as wake-up call to re-structure their Benchmark Minimum Academic Standards (BMAS), curricula, and re-training activities around culture-based mathematics education.

vi. Government at the Local, State and Federal levels should ride on the outcomes of this study to maximize the wealth derivable from the cultural diversity of the peoples and cultures of Nigeria. The under-utilized heritage sites across the country can be revived to their full potential by linking to their associated mathematical dimensions. Relevant agencies of government should organize cultural expeditions to these cultural sites, artefacts, and festivals to revamp indigenous knowledge systems, rebuild cultural and moral values in the citizenry, and generate more income. The Web-based Ethnomathematics Instructional Content Repository is open to all collaborations in this regard.

Author contributions: All authors have sufficiently contributed to the study, and agreed with the results and conclusions.

Funding: This study emerged out of a PhD Programme sponsored by Joseph Sarwuan Tarka University, Makurdi, NIGERIA

Declaration of interest: No conflict of interest is declared by authors. 


\section{REFERENCES}

Abah, J. A. (2016). Recency bias in the era of big data: The need to strengthen the status of history of mathematics in Nigerian schools. Advances in Multidisciplinary Research Journal, 2(4), 241-248. http://media.wix.com/ugd/185b0a_9b1253273fea46768d1d96dcd 03f4887.pdf

Abah, J. A. (2017). Viewing basic math through the lens of history: Undergraduates' reflective learning in a history-augmented mathematics classroom. Waikato Journal of Education, 22(4), 33-48. https://doi.org/10.15663/wje.v22i4.557

Abah, J. A. (2018a). A mathematical portrayal of a Christmas carol for Nigerian basic education: The mathematics in the twelve days of Christmas. Indian Journal of Arts, 8, 43-57. http://www.discoveryjournals.org/arts/current_issue/2018/A4.pdf

Abah, J. A. (2018b). Mathematics in the cultural practices of the Orokam people of Nigeria: Insights into the educational relevance of the i'tche game. International Journal for Innovative Research in Multidisciplinary Field, 4(6), 164-171. http://www.ijirmf.com/wpcontent/uploads/201806027.pdf

Abah, J. A., Age, T. J., \& Okoronkwo, M. O. (2018). Returning responsibility to the home: Outcomes of background checks on low and high achievers in middle basic mathematics in North Bank suburb of Makurdi, Nigeria. Journal on Efficiency and Responsibility in Education and Science, 11(2), 29-37. https://doi.org/10.7160/eriesj.2018.110202

Abah, J. A., Anyagh, P. I., \& Age, T. J. (2017). A flipped applied mathematics classroom: Nigerian university students' experience and perceptions. ABACUS: The Journal of the Mathematical Association of Nigeria, 42(1), 78-87. https://www.researchgate.net/publication/320065760_A_FLIPPED_APPLIED_MATHEMATICS_CLASSROOM_NIGERIAN_UNIVERSITY_ STUDENTS\%27_EXPERIENCE_AND_PERCEPTIONS

Abah, J. A., Iji, C. O., \& Abakpa, B. O. (2018). Blown Away in the Wind of Change: Can Extinct School Folktales be awakened through Mathematics Storytelling in Nigerian Basic Education? International Journal on Emerging Mathematics Education (IJEME), 2(2), 165178. http://journal.uad.ac.id/index.php/IJEME/article/download/10561/pdf_28

Agbo-Egwu, A. O., Abah, J. A., \& Abakpa, B. O. (2018). Perceptions of tech-augmented learning in basic mathematics among university students: A case of matrix algebra tools. International Refereed Journal of Arts, Science \& Commerce, 6(1), 121-131. https://loop.frontiersin.org/publications/51890541

Aladwani, A. M., \& Palvia, P. C. (2002). Developing and validating an instrument for measuring user-perceived web quality. Information \& Management, 39, 467-476.

Anyagh, P. I., Honmane, O., \& Abah, J. A. (2018). Secondary School Students' Perception of Teachers' Attitude towards Learning in Mathematics in Wukari Metropolis, Taraba State, Nigeria. International Journal of Research and Review, 5(5), 69-75. http://ijrrjournal.com/IJRR_Vol.5_Issue.5_May2018/IJRR0012.pdf

Anyagh, P. I., O'kwu, E. I. \& Imoko, B. I. (2016). Impact of using Tiv language for teaching and learning mathematics on students' achievement in Benue State. Asia Pacific Journal of Education, Arts and Sciences, 3(1), 94-98.

Arroyo, R. F., Hornos, M. J., \& Montes, R. (2007). Evolution of the design and implementation of Tutor: A web-based educational system for university course. In R. Moreno-Diaz (Ed.), EUROCAST 2007, LNCS 4739 (pp. 352-359). Springer-Verlag.

Bahia, K., \& Suardi, S. (2019). The state of mobile internet connectivity 2019. GSMA.

Bannan, B. (2010). The integrative learning design framework: An illustrated example from the domain of instructional technology. In T. Plomp \& N. Nieveen (Eds.), An introduction to educational design research. Proceedings of the Seminar conducted at the East China University, Shanghai (PR China), November 23-26, 2007 (pp. 53-72). SLO Netherlands Institute for Curriculum Development.

Bannan-Ritland, B. (2003). The role of design in research: The integrative learning design framework. Educational Researcher, $32(1), 21-24$. https://doi.org/10.3102/0013189x032001021

Barkatsas, A. (2004). A new scale for monitoring students' attitude for learning mathematics with technology. St. Joseph's College. pp 1-8.

Benue State Government (2015). Historical background. http://www.benuestate.gov.ng/wp/about_us/historical-background/

Benue State Ministry of Education, Science and Technology (2019). School statistics. Ministry of Education, Science and Technology Makurdi.

Bernardes, A. \& Rogue, T. (2015). Reflecting on meta-discursive rules through episodes from the history of matrices. In E. Barbin, U. T. Jankvist, \& T. H. Kjeldsen (Eds.), History and epistemology in mathematics education. Proceedings of the Seventh European Summer University held 14-18 July, 2015 at Copenhagen, Denmark (pp. 153-167).

Booth, D., \& Jansen, B. J. (2010). A review of methodologies for analyzing websites. In A. Tatnall (Ed.), Web technologies: Concepts, methodologies, tools, and applications (pp. 145-166). IGI Global.

Broadband Commission Working Group on Education (2013). Technology, broadband and education: Advancing the education for all agenda (pp. 1-40). UNESCO.

BuiltWith (2019). CMS usage distribution in the top 1 million sites. https://trends.builtwith.com/cms

Burns, B. A. (2010). Pre-service teachers' exposure to using the history of mathematics to enhance their teaching of high school mathematics. IUMPST: The Journal, 4(Curriculum).

Butuner, S. O. (2015). Using history of mathematics to teach volume formula of frustum pyramids: Dissection method. Universal Journal of Educational Research, 3(12), 1034-1048. https://doi.org/10.13189/ujer.2015.03.1213 
Colao, J. J. (2012). With 60 million websites, WordPress rules the web. So where's the money? https://www.forbes.com/sites/jjcolao/2012/09/05/the-internet-mother-tongue/

Costa, C., Alves, J. M., \& Guerra, M. (2015). Ancestral Chinese method for solving linear systems of equations seen by a ten years old Portuguese child. In E. Barbin, U. T. Jankvist, \& T. H. Kjeldsen (Eds.), History and epistemology in mathematics education. Proceedings of the Seventh European Summer University held 14-18 July, 2015 at Copenhagen, Denmark (pp. 169-182).

Craig, D. J. (2009). Defining a $21^{\text {st }}$ century education (pp. 1-79). The Centre for Public Education.

D’Ambrosio, U. (1987). Reflections on ethnomathematics. International Study Group on Ethnomathematics Newsletter, 3(1).

D’Ambrosio, U. (1994). Cultural framing of mathematics teaching and learning. In R. Biehler, R. W. Scholz, R. Straber, \& B. Winkelmann (Eds.), Didactics of Mathematics as a Scientific Discipline, 443-455.

D’Ambrosio, U. (2001a). Ethnomathematics: Link between traditions and modernity. Sense Publisher Publishers.

D'Ambrosio, U. (2001b). What is ethnomathematics, and how can it help children in schools? Teaching Children Mathematics, $7(6), 308$.

Dahal, J. (2011). Eyes don't lie: Understanding users' first impressions on website design using eye tracking (Master's thesis). Missouri University of Science and Technology.

Dankaro, J. T., \& Agoom, P. H. (2015). The imperatives of Tiv oral poetry and its influence on oral language development among Tiv children. Global Journal of Art and Social Science Education, 3(4), 107-110.

Domite, M. D. C., \& Pais, A. S. (2009). Understanding ethnomathematics from its criticisms and contradictions. Proceedings of CERME 6, January $28^{\text {th }}$-February $1^{\text {st }} 2009$, Lyon, France.

Easterday, M. W., Lewis, D. R., \& Gerber, E. M. (2014). Design-based research process: Problems, phases, and applications. Learning and Becoming in Practice. The International Conference of the Learning Science (ICLS) 2014, Proceedings Volume 1, pp 317-324.

Ebby, C., Lim, V., Reinke, L., Remillard, J., Magee, E., Hoe, N., \& Cyrus, M. (2011). Community based mathematics project: Conceptualizing access through locally relevant mathematics curricula. Perspectives on Urban Education, Spring 2011 (pp. 11-18).

Edutopia (2007). What is successful technology integration? http://www.edutopia.org/technology-integration-guide-description

Epper, R. M., \& Baker, E. D. (2009). Technology solutions for developmental math: An overview of current and emerging practices. Journal of Developmental Education, 26(2), 4-23.

Examination Office Records (2019). Student enrolment statistics. UAM, BSU, COE Oju, and COE Katsina Ala.

Ezeife, A. N. (2011). A cultural and environmental spin to mathematics education: Research implementation experience in a Canadian aboriginal community. First Nations Perspectives, 4(1), 2-39.

Ezeigbo, A. T. (2013). The relevance of oral tradition: Folklore and the education of Nigerian youths. Contemporary Experiences: Journal of African Humanities, 1(1), 128. https://submission.scholasticahq.com/api/v1/attachments/340/download

Fouze, A. Q., \& Amit, M. (2018). Development of mathematical thinking through integration of ethnomathematics folklore game in math instruction. Eurasia Journal of Mathematics, Science and Technology Education, 14(2), 617-630.

Freudenthal, H. (1968). Why to teach mathematics so as to be useful. Education Studies in Mathematics, 1, 3-8.

Freudenthal, H. (1971). Geometry between the devil and the deep sea. Educational Studies in Mathematics, 3, 413-435.

Freudenthal, H. (1973). Mathematics as an educational task. Reidel Publishing.

Freudenthal, H. (1991). Revisiting mathematics education. China Lectures. Kluwer

Garmpis, A. (2011). Design and development of a web-based interactive software tool for teaching operating systems. Journal of Information Technology Education, 10, 1-17.

Gauch, S. \& Xand, Z. (2000). Incorporating quality metrics in centralized/distributed information retrieval on the World Wide Web. Proceedings of $23^{\text {rd }}$ Annual International AGM/SIGIR Conference, Athens, Greece (pp. 288-295).

Govaerts, S., Cao, Y., Faltin, N., Cherradi, F. \& Gillet, D. (2015). Tutoring teachers - Building an online tutoring platform for the teacher community. In M. Ebner et al. (Eds.), EiED 2014, CCIS 486 (pp. 39-51). https://doi.org/10.1007/978-3-319-22017-8_4

Gravemeijer, K. (2008). RME theory and mathematics teacher education. In D. Tirosh \& T. Wood (Eds.), Tools and processes in mathematics teacher education (pp. 283-302). Sense Publishers.

Guillemette, D. (2015). A conceptual and methodological framework anchored in sociocultural approaches in mathematics education for the investigation of Depaysement Epistemologique. In E. Barbin, U.T. Jankvist \& T.H. Kjeldsen (Eds.), History and epistemology in mathematics education. Proceedings of the Seventh European Summer University held 14-18 July, 2015 at Copenhagen, Denmark (pp. 153-167).

Hayes, D. (2014). WordPress and the front controller design pattern. https://wpshout.com/wordpress-front-controller

Heeffer, A. (2006). The methodological relevance of the history of mathematics for mathematics education. http://logica.ugent.be/albrecht/thesis/Thailand2006.pdf

HOME \& OpenupEd (2015). Definition massive open online courses (MOOCs) version 1.1 . http://www.openuped.eu/images/docs/Definition_Massive_Open_Online_Courses.pdf

Horton, C. (2019). Does "last painted hero" time have an impact on SEO and search engine rankings? https://www.quora.com/Does-LastPainted-Hero-time-have-an-impact-on-SEO-and-search-engine-rankings

Hsu, T.-Y., Ke, H.-R., \& Yang, W.-P. (2006). Unified knowledge-based content management for digital archives in museums. The Electronic Library, 24(1), 38-50. https://doi.org/10.1108/02640470610649236 
Iji, C. O., \& Abah, J. A. (2018). Mathematics education for all through information technology innovations. ABACUS: The Journal of the Mathematical Association of Nigeria, 43(1), 89-100. https://doi.org/10.5281/zenodo.1409516

Iji, C. O., \& Abah, J. A. (2019). Internet skills as a measure of digital inclusion among mathematics education students: Implications for sustainable human capital development in Nigeria. International Journal of Education and Knowledge Management (IJEKM), 2(1), 1-16. https://rpajournals.com/wp-content/uploads/2019/02/IJEKM-01-2019-06.pdf

Iji, C. O., Abah, J. A., \& Anyor, J. W. (2018). Educational cloud services and the mathematics confidence, affective engagement, and behavioral engagement of mathematics education students in public universities in Benue State, Nigeria. International Journal of Teaching and Learning in Higher Education, 30(1), 47-60. http://www.isetl.org/ijtlhe/articleView.cfm?id=2825

Iji, C.O., Abah, J. A., \& Anyor, J.W. (2017). Impact of cloud services on students' attitude towards mathematics education in public universities in Benue State, Nigeria. International Journal of Research in Education and Science (IJRES), 3(1), $228-244$. http://dergipark.ulakbim.gov.tr/ijres/article/download/5000202010/5000179858

Iluno, C., \& Taylor, J. I. (2013). Ethnomathematics: The key to optimizing learning and teaching in mathematics. IOSR Journal of Research \& Method in Education, 3(1), 53-57.

Innovation Unit (2014). $21^{\text {st }}$ century learning. http://www.innovationunit.org/knowledge/our-ideas/21st-century-learning

Italiano, E. (2014). Community, contemplation, and computers: The role of technology in education. http://www.thepublicdiscourse.com/2014/02/11789/

Iversen, E. \& Jonsdottir, G. (2018). A bit more than a fly on the wall: Roles and responsibilities in design-based research. Designs for Learning, 10(1), 18-28. https://doi.org/10.16993/dfl.79

Jung H., Jun W., \& Gruenwald L. (2001) A Design and Implementation of Web-Based Project-Based Learning Support Systems. In W. Kim, T. W. Ling, Y. J. Lee, \& S. S. Park (Eds.), The human society and the internet internet-related socio-economic issues (pp. 354-367). HSI 2001. Lecture Notes in Computer Science, vol 2105. Springer.

Kanaiaupuni, S. (2007). A brief overview of culture-based education: An annotated bibliography (pp. 1-4). Kamehameha Schools Research and Evaluation Division.

Kartam, N., \& Al-Rashaid, K. (2002). Design and implementation of web-based multimedia techniques for construction education. International Journal of Engineering Education, 18(6), 682-696.

Katmada, A., Mavridis, A. \& Tsiatsos, T. (2014). Implementing a game for supporting learning in mathematics. Electronic Journal of eLearning, 12(3), 230-242.

Kemp, S. (2019). Digital 2019: Global digital overview. https://datareportal.com/reports/digital-2019-global-digital-overview

Kilpatrick, J., \& Findell, B (2001). Adding it up: Helping children learn mathematics. National Academy Press

Krejcie, R. V., \& Morgan, D. W. (1970). Determining sample size for research activities. Educational \& Psychological Measurement, 30, 607610.

Kuo, T., Lu, I.-Y., Huang, C.-H., \& Wu, G.-C. (2005). Measuring users' perceived. portal service quality - an empirical study. Total Quality Management, 16(3), 309-320.

Kurumeh, M. S. (2004). Effect of ethnomathematics approach on students' achievement and interest in geometry and mensuration (Unpublished PhD Dissertation), Faculty of Education, University of Nigeria Nsukka.

Kurumeh, M. S., Onah, F. O. \& Mohammed, A. S. (2012). Improving students' retention in junior secondary school statistics using ethnomathematics teaching approach in Obi and Oju Local Government Areas of Benue State, Nigeria. Greener Journal of Educational Research, 2(3), 054-062.

Kurumeh, M. S., Onah, F. O., \& Mohammed, A. S. (2012). Improving students' retention in junior secondary school statistics using the ethnomathematics teaching approach in Obi and Oju Local Government Areas of Benue State, Nigeria. Greener Journal of Educational Research, 2(3), 054-062.

Laja, P. (2019). First impressions matter: Why great visual design is essential. https://cxl.com/blog/first-impressions-matter-theimportance-of-great-visual-design/

Lavie, T. \& Tractinsky, N. (2004). Assessing dimensions of perceived visual aesthetics of web sites. International Journal of HumanComputer Studies, 60, 269-298.

Leibowitz, G. (2015). The billion dollar tech company with no offices or email. https://www.linkedin.com/pulse/billion-dollar-techcompany-offices-email-glenn-leibowitz

Liu, Y. (2003). Developing a scale to measure the interactivity of web sites. Journal of Advertising Research, 43(02), $207-216$.

Loiacono, E. T., Watson, R. T., \& Goodhue, D. L. (2002). WebQual: A measure of web sites quality. American Marketing Association (AMA) Winter Educators Conference, 13, 432-438.

Lokesh, U. (2013). Technology and its role in $21^{\text {st }}$ century education. http://www.edtechreview.in/trends-insights/insights/277-role-oftechnology-in-21st-century

MachMetrics (2018) Average Page Load Times for 2018 - How does your compare? https://www.machmetrics.com/speed-blog/averagepage-load-times-websites-2018/

Masoumi, D. \& Lindstrom, B. (2009). Foundations of cultural design in e-learning. International Journal of Internet and Enterprise Management, 6, 124-142. 
Miller, L. (2020). What is user experience (UX) in website design. https://hackernoon.com/what-is-user-experience-ux-in-website-designrlk631sk

Mondi, M., Woods, P. \& Rafi, A. (2008). A 'uses and gratification expectancy model' to predict students' perceived e-learning experience. Educational Technology \& Society, 11(2), 241-261.

Mondi, M., Woods, P., \& Rafi, A. (2007). Students' 'uses and gratification expectancy' conceptual framework in relation to e-learning resources. Asia Pacific Education Review, 8(3), 435-449.

Moustakis, V., Litos, C., Dalivigas, A. \& Tsironi, L. (2004). Website Quality Assessment Criteria. Proceedings of Ninth International Conference on Information Quality (IQ 2004), November 5-7, 2004 (pp. 59-73).

Neel, K. S. (2010). Ability to learn mathematics for Aboriginal1 students increases if the context, personal and cultural relevance are meaningful [Paper presentation]. AARE Annual Conference, Melbourne, Australia. Paper Code 1779 (pp. 1-14).

Nouri, J., Spikol, D., \& Cerratto-Pargman, T. (2016). A learning activity design framework for supporting mobile learning. Designs for Learning, 8(1), 1-12. https://doi.org/10.16993/dfl.67

Ofoegbu, E. O., Fayemiwo, M. A., Omisore, M. O. \& Olarenwaju, P. O. (2014). A web portal architectural design and implementation for private universities in Nigeria. International Journal of Scientific and Research Publications, 4(9), 2014.

Partnership for $21^{\text {st }}$ Century Skills (2002). Learning for the $21^{\text {st }}$ century: A report and mile guide for $21^{\text {st }}$ century skills. Partnership for $21^{\text {st }}$ Century Skills, 1-5.

Plomp, T. (2010). Educational design research: An introduction. In T. Plomp \& N. Nievwwn (Eds.), An introduction to educational design research. Proceedings of the Seminar conducted at the East China Normal University, Shanghai (PR China), November 23-26, 2007. SLO Netherlands Institute for Curriculum Development.

Richey, R. C., Klein, J. D., \& Nelson, W. A. (2004). Developmental research: Studies of instructional design and development. In D. Jonassen (Ed.), Handbook of research for educational communications and technology ( $2^{\text {nd }}$ ed., pp. 1099-1130). Lawrence Erlbaum Associates Inc.

Rosa, M. \& Shirley, L. (2016). Introduction. In G. Kaiser (Ed.), Current and future perspectives of ethnomathematics as a program. ICME-13 Topical Surveys (pp. 1-4). Springer. https://doi.org/10.1007/978-3-319-30120-4_3

Rosa, M., \& Orey, D. (2010). Ethnomodeling as a pedagogical tool for the ethnomathematics program. Revista Latinoamericana de Ethnomathematica, 3(2), 14-23.

Santos, H. B., Schrepp, M., Isal, R. Y. K., Utomo, A. Y. \& Priyogi, B. (2016). Measuring user experience of the student-centred e-learning environment. Journal of Educators Online, 13(1), 58-79. https://doi.org/10.9743/JEO.2016.1.5

Sauro, J. (2015). SUPR-Q: A comprehensive measure of the quality of the website user experience. Journal of Usability Studies, 10(2), 6886.

SETDA (2015). Ensuring the quality of digital content for learning: Recommendation for K12 education. https://www.setda.org/wpcontent/uploads/2015/03/Digital_brief_3.10.15c.pdf

Sidjanski, D. (2010). European cultural heritage and the role of science and mathematics [Keynote speech]. Bayreuth Conference 2010 on $21^{\text {st }} \quad$ September, 2010. http://fibonacci.uni-bayreuth.de/index.php?elD=tx_nawsecuredl\&u=0\&file=fileadmin/Dokumente/ conferences/bayreuth2010/Intervention_Ds_EuropeanCulturalHeritage.pdf

The Design-Based Research Collective (2003). Design-based research: An emerging paradigm for educational inquiry. Educational Researcher, 32(1), 5-8.

Thisday (2012). Benue's Opaque Budget. An article in Thisday Newspaper. http://www.thisdaylive.com/articles/benue-s-opaquebudget/114605/

Thomas, P. Y. (2011). Cloud computing: A potential paradigm for practicing the scholarship of teaching and learning. Electronic Library, 29(2), 214-224.

Thomaskutty, P. G. \& George, M. (2007). Mathematics and civil society. http://math.arizona.edu/ atp-mena/conference/proceedings/ Thomaskutty_Math_Civil_Society.doc

Troutman, J. S. \& McCoy, L. (2008). Re-membering mathematics: The effect of culturally relevant lessons in math history on students' attitude. The Journal of Mathematics and Culture, 3(1), 14-15.

Ulrich, K. T. \& Eppinger, S. D. (2000). Product design and development ( $2^{\text {nd }}$ Ed.). Irwin/McGraw-Hill.

UNESCO (2008). Developing culturally contextualized mathematics resource materials: Capturing local practices of Tamang and Gopali Communities [pp. 1-15]. UNESCO Office in Kathmandu.

Vainio, T., Walsh, T. \& Varsaluoma, J. (2014). Cross-cultural design of mobile mathematics learning for South African schools. IADIS International Journal on WWW/Internet, 12(1), 81-93.

Van de Rakt, M. (2018). SEO basics: What is site structure and why is it important? https://yoast.com/site-structure

Van den Heuvel-Panhizen, M. (2003). The didactical use of models in realistic mathematics education: An example from a longitudinal trajectory on percentage. Educational Studies in Mathematics, 54, 9-35.

Van den Heuvel-Panhuizen, M., \& Drijvers, P. (2014). Realistic mathematics education. In S. Lerman (Ed.), Encyclopedia of Mathematics Education. Springer Science and Business Media. https://doi.org/10.1007/978-94-007-4978-8

W3Techs (2019). Usage of content management systems. https://w3techs.com/technologies/overview/content_management/all 
Walker, D. (2006). Toward productive design studies. In J. van den Akker, K. Gravemeijer, S. McKenney, \& N. Nieveen (Eds.), Educational Design Research [pp. 9-18].

Wang, P. S., Zhou, Y. \& Zou, X. (2004). Web-based mathematics education: MeML design and implementation. Proceedings of Conference on Information Technology: Coding and Computing, 1, 169-175.

WordPress (2019). WordPress plugins. https://wordpress.org/plugins

Wozney, L., Venkatesh, V. \& Abrami, P. (2006). Implementing computer technologies: Teachers' perception and practices. Journal of Technology and Teacher Education, 14, 173-207.

Yao, R.-F. (2016). Creating learning environments for indigenous students through culture-based math modules. Universal Journal of Educational Research, 4(8), 1809-1814. https://doi.org/10.13189/ujer.2016.040810

Yusuf, M. W., Saidu, I., \& Halliru, A. (2010). Ethnomathematics: A case of Wasakwakwalwa (Hausa culture puzzles) in Nothern Nigeria. International Journal of Basic \& Applied Sciences, 10(1), 11-16. 


\section{APPENDIX A}

\section{Web-Based Ethnomathematics Instructional Content Repository Assessment Questionnaire (WEICRAQ)}

This survey requires that you to kindly assess the entire experience available on the VillageMath educational platform.

To assess the quality of this website, you first have to visit https://villagemath. net and explore the features of the platform as much as you can. Your candid rating of the content, navigation, structure, appearance, and uniqueness of the ethnomathematics repository will help in the ongoing improvement of the platform.

\section{Basic information}

Choose a category:

- Pre-Service Mathematics Teacher (Mathematics Education Student in University or College of Education)

- In-Service Mathematics Teacher (Regular Mathematics Teacher)

Location of Study/Service:

- Benue State Nigeria

O Other (Outside Benue State Nigeria)

\section{Quality of the web-based ethnomathematics instructional content repository in terms of content}

On a four-point scale where Very High = 4; High = 3; Low = 2; and Very Low = 1, how would you rate the quality of the CONTENT on villagemath.net based on the following statements?

\begin{tabular}{|c|c|c|c|c|c|}
\hline S/NO. & Item & $\begin{array}{l}\text { Very } \\
\text { High }\end{array}$ & High & Low & $\begin{array}{l}\text { Very } \\
\text { Low }\end{array}$ \\
\hline 1 & Information on villagemath.net is current and timely for mathematics teachers. & & & & \\
\hline 2 & Information on villagemath.net is accurate for mathematics teachers. & & & & \\
\hline 3 & Information on villagemath.net is relevant to mathematics teachers. & & & & \\
\hline 4 & Information on the website is rich in detail for mathematics teachers. & & & & \\
\hline 5 & Mathematics teachers' privacy is protected on villagemath.net & & & & \\
\hline $6^{*}$ & The content of the website is not useful to mathematics teachers. & & & & \\
\hline 7 & The content of villagemath.net is complete. & & & & \\
\hline 8 & The content of the website is clear. & & & & \\
\hline 9 & The content of the website is concise. & & & & \\
\hline $10^{*}$ & Mathematics teachers cannot rely on the villagemath.net website. & & & & \\
\hline 11 & The site provides reliable ethnomathematics content. & & & & \\
\hline
\end{tabular}

\section{Quality of the web-based ethnomathematics instructional content repository in terms of navigation}

On a four-point scale where Very High = 4; High = 3; Low = 2; and Very Low = 1, how would you rate the quality of the NAVIGATION on villagemath.net based on the following statements?

\begin{tabular}{|c|c|c|c|c|c|}
\hline S/NO. & Item & $\begin{array}{l}\text { Very } \\
\text { High }\end{array}$ & High & Low & $\begin{array}{l}\text { Very } \\
\text { Low }\end{array}$ \\
\hline 1 & Web pages on villagemath.net load fast. & & & & \\
\hline 2 & $\begin{array}{l}\text { Mathematics teachers visiting the villagemath.net website are able to obtain the information } \\
\text { they want without any delay. }\end{array}$ & & & & \\
\hline $3^{*}$ & The website villagemath.net is not available all the time. & & & & \\
\hline 4 & Links on the villagemath.net platform lead to instantaneous information. & & & & \\
\hline $5^{\star}$ & Accessing information on villagemath.net is difficult. & & & & \\
\hline 6 & Information category on the website is simple and straightforward. & & & & \\
\hline 7 & $\begin{array}{l}\text { The website has many interactive service features such as comments, contact, and forum that } \\
\text { can be easily accessed. }\end{array}$ & & & & \\
\hline 8 & The villagemath.net website has adequate search facilities. & & & & \\
\hline 9 & The site exhibits easy orientation for different devices and browsers. & & & & \\
\hline 10 & Learning to operate the website is easy. & & & & \\
\hline 11 & Mathematics teachers are able to find what they need quickly on this website. & & & & \\
\hline $12^{*}$ & The layout available on villagemath.net makes it difficult to navigate the platform. & & & & \\
\hline 13 & Hyperlinks on the website are valid. & & & & \\
\hline
\end{tabular}

\section{Quality of the web-based ethnomathematics instructional content repository in terms of structure and design}

On a four-point scale where Very High = 4; High $=3$; Low $=2$; and Very Low $=1$, how would you rate the quality of the STRUCTURE/DESIGN of villagemath.net based on the following statements? 


\begin{tabular}{|c|c|c|c|c|c|}
\hline S/NO. & Item & $\begin{array}{l}\text { Very } \\
\text { High }\end{array}$ & High & Low & $\begin{array}{l}\text { Very } \\
\text { Low }\end{array}$ \\
\hline 1 & Services on villagemath.net is easy to locate. & & & & \\
\hline 2 & The structure of the website shows originality in design. & & & & \\
\hline 3 & The website has a fast loading speed. & & & & \\
\hline $4^{\star}$ & The site is not adaptable to all devices and screens. & & & & \\
\hline 5 & The villagemath.net website has a functional sitemap. & & & & \\
\hline 6 & The website is compatible with different web browsers. & & & & \\
\hline 7 & The site has a simple background schemes. & & & & \\
\hline 8 & Information structure on villagemath.net reflects order and togetherness of information. & & & & \\
\hline 9 & Visiting the site does not require any specialized software. & & & & \\
\hline 10 & The villagemath.net site is responsive in providing information in real time conditions. & & & & \\
\hline 11 & $\begin{array}{l}\text { Links to share topics from villagemath.net to different social media platforms (such as twitter } \\
\text { and facebook) makes the site desirable. }\end{array}$ & & & & \\
\hline 12 & $\begin{array}{l}\text { The availability of discussion forums on villagemath.net makes the platform professional for } \\
\text { mathematics teachers. }\end{array}$ & & & & \\
\hline 13 & $\begin{array}{l}\text { The user authentication feature of villagemath.net provides additional security for mathematics } \\
\text { teachers on the platform. }\end{array}$ & & & & \\
\hline
\end{tabular}

\section{Quality of the web-based ethnomathematics instructional content repository in terms of appearance and multimedia}

On a four-point scale where Very High $=4$; High $=3$; Low $=2$; and Very Low $=1$, how would you rate the quality of the APPEARANCE/MULTIMEDIA of villagemath.net based on the following statements?

\begin{tabular}{|c|c|c|c|c|c|}
\hline S/NO. & Item & $\begin{array}{l}\text { Very } \\
\text { High }\end{array}$ & High & Low & $\begin{array}{l}\text { Very } \\
\text { Low }\end{array}$ \\
\hline 1 & Web pages on villagemath.net are visually attractive & & & & \\
\hline 2 & The villagemath.net website looks organized. & & & & \\
\hline $3^{*}$ & The website looks unattractive. & & & & \\
\hline 4 & The website villagemath.net uses fonts properly. & & & & \\
\hline 5 & The website uses colours properly. & & & & \\
\hline 6 & The villagemath.net website uses multimedia features properly. & & & & \\
\hline 7 & The appearance is gratifying with each visit to villagemath.net & & & & \\
\hline $8^{\star}$ & The display pages within the website are not easy to read. & & & & \\
\hline 9 & The website labels are easy to understand. & & & & \\
\hline 10 & The website has a clean and simple presentation. & & & & \\
\hline 11 & The combination of image, voice and video on the site are appropriate. & & & & \\
\hline 12 & $\begin{array}{l}\text { The placement of graphics within articles on villagemath.net makes the articles more attractive } \\
\text { for reading }\end{array}$ & & & & \\
\hline
\end{tabular}

\section{Quality of the web-based ethnomathematics instructional content repository in terms of uniqueness}

On a four-point scale where Very High = 4; High = 3; Low = 2; and Very Low = 1, how would you rate the quality of the UNIQUENESS of villagemath.net based on the following statements?

\begin{tabular}{|c|c|c|c|c|c|}
\hline S/NO. & Item & $\begin{array}{l}\text { Very } \\
\text { High }\end{array}$ & High & Low & $\begin{array}{l}\text { Very } \\
\text { Low }\end{array}$ \\
\hline 1 & The website facilitates a unique two-way communication between the visitors and the site. & & & & \\
\hline 2 & $\begin{array}{c}\text { The villagemath.net website can be personalized or customized to meet mathematics teachers' } \\
\text { needs. }\end{array}$ & & & & \\
\hline 3 & The website has a reflective (catchy) name. & & & & \\
\hline 4 & The website made good use of special effects. & & & & \\
\hline 5 & $\begin{array}{l}\text { The information on villagemath.net is pretty much what every teacher needs to carry out my } \\
\text { mathematics teaching tasks. }\end{array}$ & & & & \\
\hline 6 & The website is innovative. & & & & \\
\hline $7^{\star}$ & The ideas expressed on villagemath.net are not creative. & & & & \\
\hline 8 & The website has embedded sociable features. & & & & \\
\hline 9 & The website reflects originality of provided information. & & & & \\
\hline 10 & $\begin{array}{l}\text { The type of information available from the website makes villagemath.net peculiar for } \\
\text { mathematics teachers. }\end{array}$ & & & & \\
\hline $11^{\star}$ & The villagemath.net platform is not unique in any way. & & & & \\
\hline 12 & The website is special in encouraging cultural values. & & & & \\
\hline 13 & The villagemath.net platform is unique in providing all resources in downloadable formats & & & & \\
\hline
\end{tabular}

